\title{
New Approach to the Treatment of CoV-2 Infection by Means of Immune-modulators and Non-Steroid Anti- Inflammatory Drugs
}

\author{
Marta Navarro-Zorraquino ${ }^{1 *}$, Cristina Pastor Oliver $^{2}$ and Felícito García-Álvarez ${ }^{1}$ \\ ${ }^{1}$ Department of Surgery, School of Medicine, Universidad de Zaragoza, Zaragoza, Spain \\ ${ }^{2}$ Service of Experimental Surgery, Instituto Aragonés de Ciencias de la Salud, Zaragoza, Spain \\ *Corresponding author: Marta Navarro-Zorraquino, Department of Surgery, School of Medicine, Universidad de Zaragoza, \\ Zaragoza, Spain
}

\begin{tabular}{|c|c|}
\hline ARTICLE INFO & ABSTRACT \\
\hline $\begin{array}{l}\text { Received: 慧 September 16, } 2021 \\
\text { Published: 蔧 September 23, } 2021\end{array}$ & $\begin{array}{l}\text { Coronaviruses were discovered in the } 1960 \text { s and because of their corona-like } \\
\text { shape were termed "coronaviruses"; these viruses can infect both animals and humans, } \\
\text { although the latter is not a frequent occurrence. This century has seen the worldwide } \\
\text { spread of } 3 \text { previously unknown coronaviruses. }\end{array}$ \\
\hline $\begin{array}{l}\text { Citation: Marta Navarro-Zorraquino, Cris- } \\
\text { tina Pastor Oliver, Felícito García-Álvarez. } \\
\text { New Approach to the Treatment of CoV-2 } \\
\text { Infection by Means of Immune-modula- } \\
\text { tors and Non-Steroid Anti-Inflammatory } \\
\text { Drugs. Biomed J Sci \& Tech Res 39(1)- } \\
\text { 2021. BJSTR. MS.ID.006232. }\end{array}$ & $\begin{array}{l}\text { Abbreviation's: SARS: Severe Acute Respiratory Syndrome; MERS: Middle East } \\
\text { Respiratory Syndrome Coronavirus; nCoV: New Coronavirus; WHO: World Health } \\
\text { Organization; SIRS: Systemic Inflammatory Response Syndrome; MOF: Multiorgan } \\
\text { Failure; DCs: Dendritic Cells; APCs: Antigen Presenting Cells; CRH: Corticotropin- } \\
\text { Releasing Hormone; VDR: Vitamin D Receptor; NO: Nitric oxide; COPD: Chronic } \\
\text { Obstructive Pulmonary Disease; ROS: Reactive Oxygen Species; RAS: Renin-Angiotensin } \\
\text { System }\end{array}$ \\
\hline
\end{tabular}

\section{Historical Background of the "COVID-19" Pan-} demic

The first known case of coronavirus was described as "severe acute respiratory syndrome" (SARS), which occurred on November 16, 2002, in Foshan, a city about 20 km from Guangzhou in China's Guangdong province. Since November 2002, an unknown infectious agent had caused outbreaks of an atypical pneumonia that spread throughout Guangdong province in southern China. The disease usually started with high fever and mild respiratory symptoms, but rapidly progressed to pneumonia and within a few days new cases emerged in mainland China, so that by February 2003 more than 300 cases had been reported, about one-third of which involved health care workers [1]. Persons who became infected and subsequently traveled spread the outbreak to Hong Kong [2] and from there to Vietnam, Canada, and several other countries [3]. By the end of February 2003, the disease had spread to neighboring regions and countries, was severe, could be transmitted from person to person, and appeared to cause significant outbreaks in health care workers [3,4]. On March 13, 2003, WHO issued a global alert on the disease that it termed "severe acute respiratory syndrome" (SARS) [5], and a remarkable global effort led to the identification of the SARS coronavirus (SARS-CoV). In early April of the same year [4,6], 6 outbreaks occurred in Southeast Asia, North America and Europe and led to the first pandemic of the 21st century. In July 2003 and after a total of 8,096 reported cases, including 774 deaths in 27 countries [7], no further infections were detected and the SARS pandemic was declared to be over. Five additional cases of SARS, as a result of zoonosis, occurred between December 2003 and January 2004 [8], but no further human cases of SARS have been detected since then. Infection control measures, rather than medical interventions, then put an end to the first SARS-CoV pandemic of the 21st century. However, the possibility of transmission in a variety of ways was noted. It was later shown that certain viruses, 
similar to SARS-CoV found in bats, could infect human cells without prior adaptation $[9,10]$, indicating that SARS could re-emerge [11]. Indeed, 10 years after the first occurrence of SARS-CoV, a man in Saudi Arabia died of "acute respiratory syndrome" and in his serum the "coronavirus" had been isolated, this syndrome was called "Middle East Respiratory Syndrome coronavirus" (MERS) because of its place of origin. In April 2012, several cases of "severe respiratory illness" had already occurred in a hospital in Jordan [12], these cases were retrospectively diagnosed, and considered to be human-to-human transmitted, furthermore in the United Kingdom, 3 cases of MERS were reported in September 2012 [13].

In May 2015, a single person, returning from the Middle East, initiated a nosocomial MERS outbreak in South Korea that affected 16 hospitals and 186 patients [14]. By April 26, 2016, 1,728 MERS cases, including 624 deaths, had been confirmed in 27 countries $[15,16]$. (Figure 1) In the accompanying figure, published in 2016 (copied from review paper: de Wit E, Doremalen VN, Falzarano D, et al. SARS and MERS: recent insights into emerging coronaviruses. Nat Rev Microbiol. (2016) 14: 523-34.doi: 10.1038/nrmicro.2016.81) shows as different ways of coronavirus transmission. Bats could have been the main reservoir of the coronavirus 30 years before passing to humans, due to "cross-species transmission" between bats and camels; these animals, through continuous contact with humans, could have produced the direct zoonosis that gave rise to MERS-CoV. Moreover, the detection of the virus in "palm civets"
(Chinese species) and in a "raccoon dog" (Japanese raccoon), as well as the detection of antibodies to the virus in the Chinese ferretbadger (also known as small-toothed ferret- badger) observed at a live animal market in Shenzhen, China [17] alerted researchers to the possible transmission of the virus to humans. However, these animals were only incidental hosts, as there was no evidence of SARS-CoV-like virus circulation in "palm civets," both in the wild and in breeding facilities [18]. Thus, the search for the MERS$\mathrm{CoV}$ reservoir initially focused on bats, but a serological study in dromedaries from Oman and the Canary Islands showed a high prevalence of MERS-CoV neutralizing antibodies in these animals [19]. In addition, MERS-CoV RNA was detected in swabs collected from dromedaries on a farm in Qatar that was associated with two human cases of MERS, and infectious virus was isolated from dromedaries in Saudi Arabia and Qatar [20-23], and serological tests also detected circulation of a MERS-CoV-like virus in dromedaries in the Middle East, East Africa, and North Africa. Dromedaries in Saudi Arabia harbor several viral genetic lineages [24], including those that have caused outbreaks in humans. Taken together, these data pointed to the role of dromedaries as a reservoir of MERS-CoV. The ubiquity of infected dromedaries near humans and the resulting zoonosis may explain why MERS-CoV continues to cause human infections, whereas SARS-CoV, without the continued presence of an infected intermediate host and with relatively infrequent human-bat interactions, had not caused further human infections.

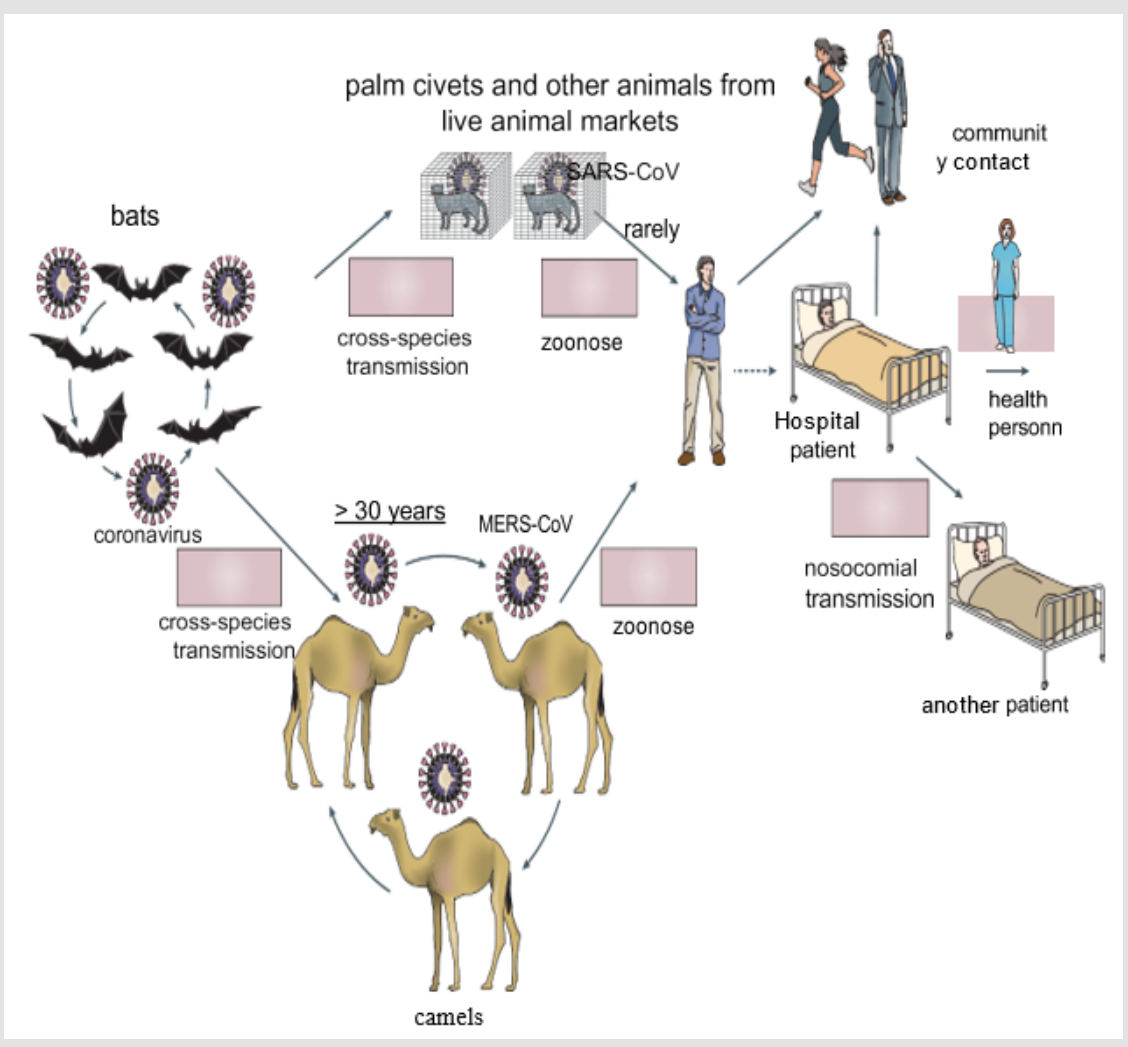

Figure 1. 
Person-to-person transmission of SARS-CoV and MERS-CoV occurred primarily through nosocomial transmission. Between 43.5 and $100 \%$ of MERS cases in individual outbreaks were hospital-related, and very similar observations were made for some of the SARS clusters [25-26]. Transmission among family members occurred in only 13 to $21 \%$ of MERS cases and 22 to $39 \%$ of SARS cases. Patient-to- patient transmission of MERS$\mathrm{CoV}$ was the most common route of infection (62-79\% of cases), whereas for SARS-CoV, infection of health care workers by infected patients was very common (33-42\%) [25]. The predominance of nosocomial transmission is probably due to the fact that substantial virus shedding occurs only after symptom onset [27-28], when most patients are already seeking medical care [29]. An analysis of hospital surfaces after treatment of patients with MERS showed the ubiquitous presence of viral RNA in the environment for several days after patients stopped testing positive [30]. In addition, many SARS or MERS patients were infected through "superpropagators" [25-27,31-33]. As of 2016, it had already been provided, in various publications, that the key features of these viruses are: the predominance of nosocomial transmission, pathogenesis driven by a combination of viral replication in the lower respiratory tract and an aberrant host immune response, and several potential treatments for SARS and MERS in animal models and "in vitro" had also been suggested, including small-molecule protease inhibitors, neutralizing antibodies and inhibitors of the host immune response.

\section{Current Pandemic COVID-19}

In December 2019, a new coronavirus ("nCoV") emerged in Wuhan, Hubei province in China. Attention was focused on the Huanan food market, where in addition to fish, livestock animals were also traded. However, analysis of the first 41 hospitalized patients showed that the Wuhan seafood market might not be the main source for the spread of a new virus [34]. Nevertheless, an epidemic of severe pneumonia of unknown cause soon appeared [35], and genomic sequencing of viral isolates from five pneumonia patients hospitalized from December 18 to 29, 2019, indicated the presence of a previously unknown "b-CoV" strain in patients [36]. This "new" coronavirus (nCoV) subsequently spread from the original outbreak site in China and was designated as "SARS-CoV-2" by the World Health Organization (WHO) on January 12, 2020 and the disease as "COVID-19" on February 11, 2020 [37] and this virus was confirmed to have $75-80 \%$ similarity to the coronavirus that caused severe acute respiratory syndrome (SARS-CoV) [38]From February 2020 to April 2020, the disease "COVID-19" affected 188 countries worldwide. [38] and up to July 14, 2020 the cumulative number of confirmed cases was 13.1 million people and at least 572,426 people died from SARS-CoV-2 infection [39], the incidence of deaths ranged from less than $1 \%$ to $3.7 \%$ among the different countries [40], these figures were compared with the rate of deaths from influenza which was less than $0.1 \%$ [35].

After the first pandemic period, the incidence of COVID-2 infected cases declined during the summer months and then rose again significantly from September/October 2020 to date (31 January 2021), the increase in incidence is statistically shown as a "wave", with 3/4 "waves" with "peaks", "plateaus" and "valleys" in different countries; Most European Union countries, including Spain, have experienced high levels of incidence, but the highest number of infections has been observed in Great Britain, the USA, Brazil and India, up to this point. As of January 30, 2021, the number of cases in the world since the pandemic began at the end of 2019 has been: 102,000,000, and the number of deaths: 2,210,000.

\section{The Acute Inflammatory Process}

From the clinical point of view, the disease caused by CoV-2 presents 3 fundamental stages: in the first stage the patient shows signs and symptoms similar to infection by other viruses and/ or bacteria of the respiratory tract (e.g., Influenza), in this stage the symptoms are shown to a lesser degree and the patient may even be asymptomatic. In the second stage the patient feels worse and the signs and symptoms are more evident (fever, tiredness, general malaise, anosmia, hypoacusis, etc.); this stage is definitive for the patient, who may improve in the following days until cured or worsen until reaching the third stage, which may worsen to the point that the patient has to be admitted to the ICU, where intubation and assisted respiration may even be necessary; this moment is crucial for the patient since the feared "cytokine storm" may occur. From the immunological point of view, infections by bacteria and/or viruses, accidental or provoked trauma (e.g. surgical interventions), allograft rejection and the development of neoplasms have a common point: inflammation. Inflammation is the result of multiple interactions of the systems involved in the homeostasis of the organism, mainly the immune system, which have as their first objective the localization of the process and the elimination of the aggressor agent. When the infection is aggravated by a huge excess of antigen (due to the unstoppable and rapid replication of the virus), the inflammation reaches its climax and becomes a systemic process that affects the whole organism, it is called "systemic inflammatory response syndrome" (SIRS), and in the case of COVID-19, since the respiratory system is the main system affected, it is called "SARS-CoV-2" ("systemic acute respiratory syndrome"), the response of the immune system overflows and the "cytokine storm" appears, which can lead to "multiorgan failure" (MOF) and death of the patient. In fact, from a biological point of view, tissue injury and its sequelae are involved in most medical problems and the response of living tissues to aggression is the basis and foundation of the immune response. [41-45]. 
In addition to cytokine storming, COVID-19 viral particles can also directly induce multiple organ dysfunctions. In this regard viral particles from COVID-19 infection have been identified in bronchial and alveolar type 2 epithelial cells, and in fecal and urine samples $[46,47]$. Therefore, it is suggested that multiple organ dysfunction in patients with severe COVID-19 may also be caused by a direct attack by the virus. Many authors think that the synergistic effects of both effects contribute to the "multi-organ" failure of patients with severe COVID-19 however, we and some authors believe that in fatal COVID-19 cases, severe dysfunction of the immune response is responsible to a greater degree than the direct damaging effect of the virus itself $[42,47]$. (Figure 2) When macrophages or any other "antigen presenting cell" (APC) are stimulated, the "proinflammatory" cytokines par excellence are released: IL-1, IL-6, IL-8, IL-15, IL-17, IL-18, TNFs, IFN口 and PAF (platelet-activating factor). These cytokines play a relevant role in the inflammatory process and, in turn, can give rise to the so-called "cytokine storm", the consequence of which is "systemic inflammatory response syndrome" (SIRS) and finally "multi-organ failure" (MOF), leading to death. On the other hand, as Niels Jerne (1974) said: "any stimulus capable of producing an immune response provokes a reaction comparable to the transmission of the ripples that can be observed in a pond when a stone is thrown, so that in the immune system the variation at the site of the stimulus receptor is transmitted everywhere". In "SARS" this allegory reaches a dramatic expression and encompasses not only the network of signals, which cross and intersect within the immune system, but between the different systems (coagulation, fibrinolytics, cyanins, arachidonic acid, leukotrienes and thromboxanes, the immune system itself (complement system, circulating immune complexes ICC, ADCC, NK cells, adaptive immune response: CTL and cytokines) (Figure 2).

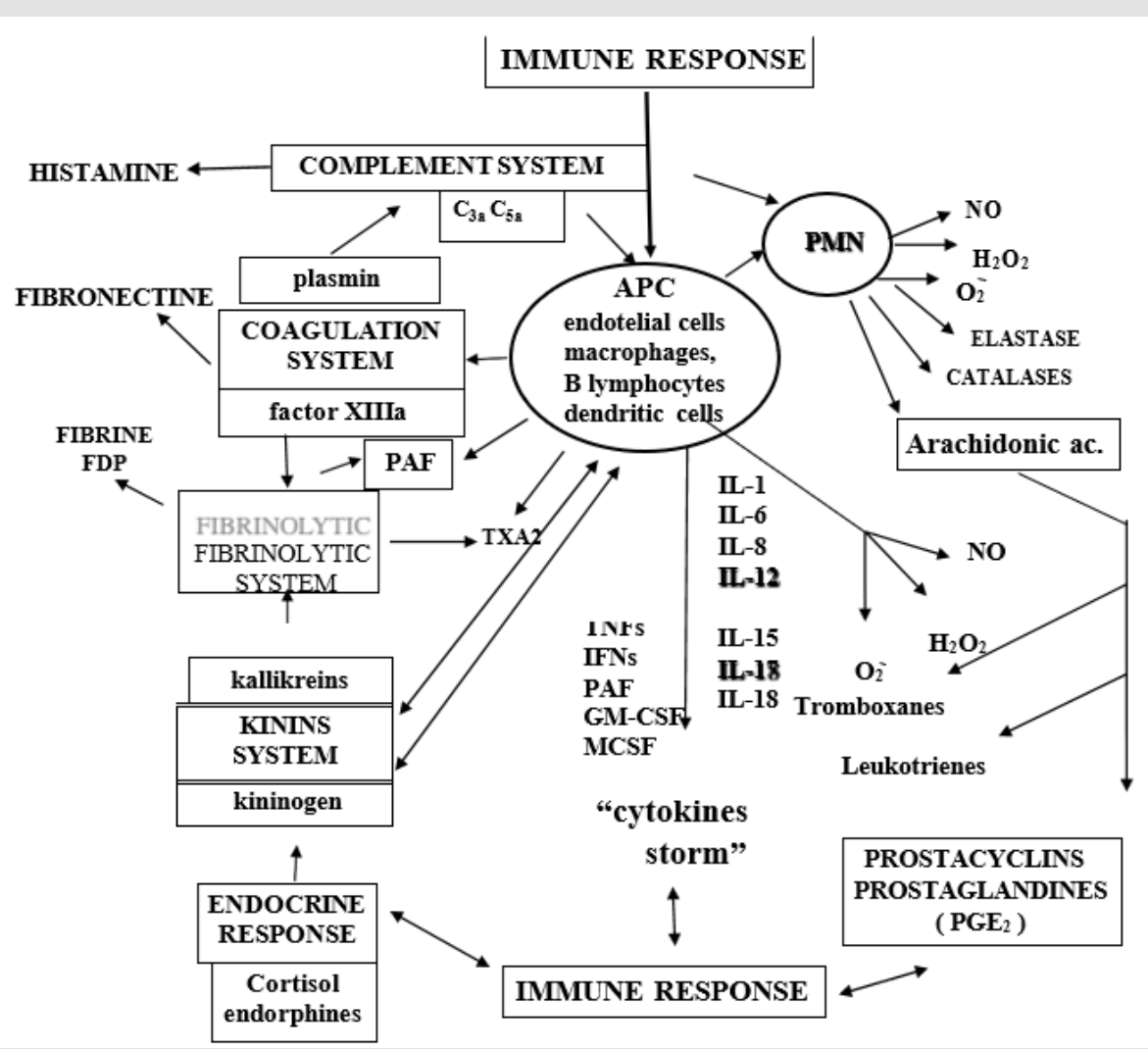

Figure 2: Navarro-Zorraquino M Immunologic response in shock and multiorgan failure. In: Navarro-Zorraquino M, editor. Immunological aspects of surgery. Zaragoza:

Prensas Universitarias de Zaragoza; 1997. p. 261-300.

For this reason, the lack of control of the servomechanisms that maintain homeostasis in any of the mentioned systems can cause an unstoppable situation of mediator release leading irremediably to tissue damage [42]. From the pathophysiological point of view, inflammation is the result of multiple interactions between the various systems of the organism, which have as their first objective the localization of the process and the elimination of the aggressor agent; this is followed by a repair process. The main physical-chemical events that occur during inflammation are: increased blood supply to the site of the attack, increased capillary permeability - which allows larger molecules than usual, such as antibodies and fractions of the complement system and other 
enzyme systems, to pass through the vascular endothelium - and the activation of leukocytes: initially neutrophils and macrophages, then lymphocytes. The development of the inflammatory reaction is controlled by cytokines, which are the intercellular messengers of the "immunocompetent" molecules, the products of the plasma enzyme systems, the coagulation, fibrinolytic, cyanin and complement systems, vasoactive mediators released from mast cells, basophils and platelets, and endothelial adhesion molecules. Since CoV-2 exhibits tropism to the lung, the initiation of the immune response against coronavirus begins with direct infection of the bronchus and bronchiole epithelium. First, antigen-independent innate immunity provides the first line of defense of leukocytes against microorganisms. The "innate immune response involves several cell types, including leukocytes, neutrophils, eosinophils, eosinophils, basophils, monocytes, macrophages, lung epithelial cells, mast cells, and NK cells. After initial CoV-2 infection, dendritic cells (DCs) residing in the lungs become activated and change to "antigen presenting cells" (APCs).

\section{IMMUNE RESPONSE PATHWAYS OF ACTIVATION: "INFLAMMATORY","ANTI-INFLAMMATORY"AND "IMMUNOREGULATORY".}
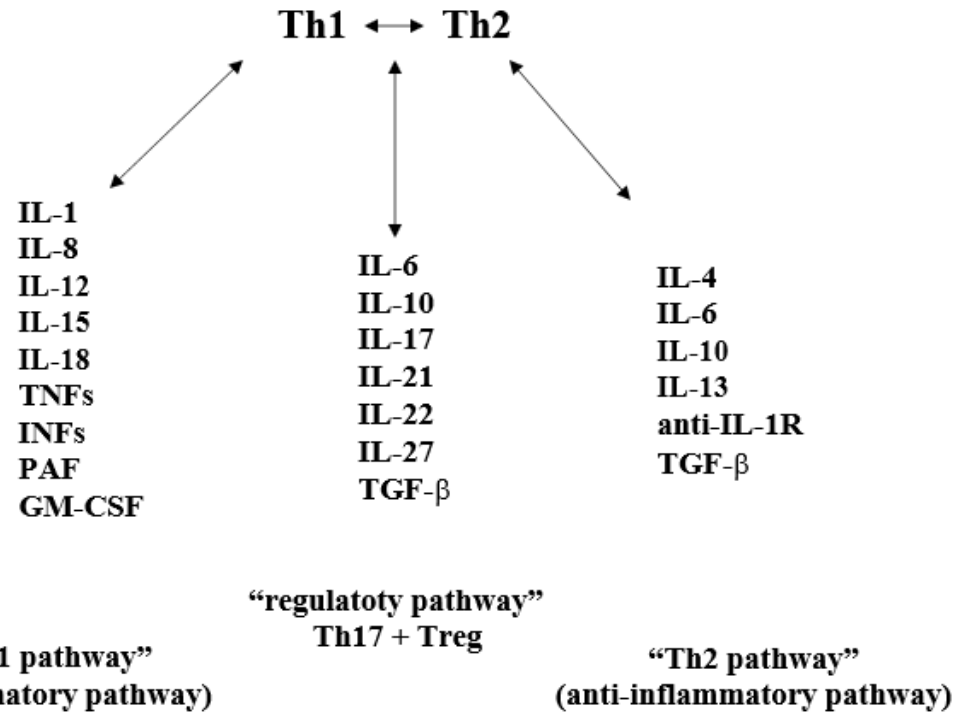

"Th2 pathway" (anti-inflammatory pathway)

"Th1 pathway" (inflammatory pathway)

Figure 3.

In thelung, DCs reside within and beneath the airway epithelium, alveolar septa, pulmonary capillaries and airway spaces. Activated APCs" cells ingest and process the antigens and migrate to the lymph nodes, in the lymph nodes the "APC cells" present the antigen in the form of $\mathrm{MHC} /$ peptide complex to the "virgin circulating $\mathrm{T}$ helper cells" (Th0), inducing the immune response. Following activation of the Th0 receptor by the MHC/peptide complex, Th2 cells are activated, proliferate and differentiate into CD4+ (Th lymphocytes) and CD8+ (cytotoxic T lymphocytes) cells. Subsequently, Th lymphocytes further differentiate into Th1 and Th2 cells, which are capable of releasing different cytokine profiles: Th1 cells drive cell-mediated immunity and release pro- inflammatory cytokines such as IFN- $\gamma$, IL-1 $\beta$, IL-12 and pro-inflammatory factors such as TNFs, IFNs, PAF, GM-CSF, MCSF; Th2 cells activate the production of antibody-producing $\mathrm{B}$ cells and release anti- inflammatory cytokines such as TGF- $\beta$, IL-4, IL-5, IL-9, IL-10 and IL-13 [42,47]. In the immune response of healthy adults with $\mathrm{CoV}-2$ infection there is a balance between Th1 and Th2 lymphocyte activity. The inflammatory reaction initiated by the immune system, through the Th1 activation pathway and with the participation of Th17 cells and various cytokines, is regulated by the immune response itself through a "regulatory servo-mechanism" involving mainly Th2 cells (considered as the main pathway of the "anti-inflammatory response"), through sub-populations of Th2 cells, called "regulatory cells": Treg (CD4+25+FOXp3 and CD8+25+FOXp3) and Th-17 cells (Figure 3). Th17 cells" regulate the response by increasing the release of "pro-inflammatory" cytokines and Treg cells" regulate the response towards the release of anti-inflammatory cytokines. (Figure 3) Navarro-Zorraquino M. Immunologic response in shock and multiorgan failure. In: Navarro-Zorraquino $\mathrm{M}$, editor. 
Immunological aspects of surgery. Zaragoza: Prensas Universitarias de Zaragoza; 1997. p. 261- 300. We wish to emphasize here that the "regulatory pathway" exerts its role by responding to the needs of the immune response, at a given time, against the corresponding antigen, by increasing the inflammatory activity of the Th1 pathway, mainly by means of Th17 cells and IL-17A, or by increasing the anti-inflammatory activity of the Th2 pathway, mainly by means of transforming growth factor $\beta$ (TGF- $\beta$ ). Since these 2 cytokines are going to be the key in the design of our research project, we will insist on them later.

\section{Systems of the Human Organism Affected by the "Cytokine Storm"}

Itis important to remember here the influence and consequences that the immune response has on the most important systems of the human organism, especially when it overflows producing the "cytokine storm". If we look at Fig. 2, we can see that this response is related to the release of histamine, activation of the coagulation, fibrinolysis and "kinins" systems, release of arachidonic acid metabolites, neuroendocrine response, release of free radicals and release of prostacyclins and prostaglandins [42]. When the complement system is activated, the different fractions are released (activation by the classical pathway begins with the $\mathrm{C} 1$ fraction, and activation by the alternative pathway begins with the $\mathrm{C} 3$ fraction), but the most important for their pathophysiological actions are the C3a and C5a fractions (called anaphylatoxins), which increase capillary permeability and produce smooth muscle contractionboth at the level of the bronchial tree and the gastrointestinal tract; the C3a fraction is capable of producing tachycardia, impairing cardiac function and inducing coronary vasoconstriction. The C3a and $\mathrm{C5}$ a fractions stimulate basophils and mast cells to release histamine, whose main action is to increase vascular permeability and smooth muscle contraction. When aggression to the organism occurs, activation of the enzymatic cascades of the complement system, kinins, coagulation and fibrinolysis occurs rapidly, as well as cell activation of PMN leukocytes, macrophages, endothelial cells and platelets. Tissue damage produced by viruses (the case of CoV2) induces platelet aggregation and adhesiveness on subendothelial collagen when the vascular endothelium is damaged, thus initiating an activation, by means of the so-called intrinsic pathway, through the activation of factor XII (Hageman's factor), which gives rise to FXIIa [42] which is an active protease; this is a key factor that directly relates the coagulation system to the so-called "kinin system", "kinins" or "kinins" (Figure 2). kinins" or "kinins" (Figure 2). FXIIa activates pre-kallikrein which becomes kallikrein and this, in turn, becomes kininogen, a high molecular weight substance, which together with factor XII and pre-kallikrein binds directly to sub- endothelial collagen, as do platelets through the mediation of Willebrand factor (Figure 2).
At the same time that activation of the coagulation system by the intrinsic pathway occurs, activation of the so-called "extrinsic pathway" can also occur, by means of tissue thromboplastin released by damaged cells; tissue thromboplastin activates the extrinsic pathway in collaboration with factor VIIa (FVIIa) causing factor X (FX) to also become an active protease -FXa-. The result of the activation of the coagulation system by both pathways is the conversion of prothrombin to thrombin, which increases platelet aggregation and induces the release of arachidonic acid metabolites, especially thromboxane A2 (TxA2) (Figure 2).This activation of the coagulation system would be implicated in the immune response to $\mathrm{CoV}-2$ and the production of clots in patients with COVID-19, especially in the most severe stage of the disease, as well as in the finding of clots in the necropsies of deceased patients. The hypothalamic-pituitary-adrenal axis responds to stimuli that represent the release of mediators and the organism's own aggressor agent in a given situation. At the present time there are numerous studies that attempt to relate different hormones, whose synthesis and release is regulated by the neuroendocrine system, with the immune response in various situations. We will refer here only to what seems to us most relevant in relation to the inflammatory response and in particular to the pathophysiology of the "cytokine response"[42].

Cortisol is the most important glucocorticoid secreted by the adrenal cortex in response to ACTH and corticotropin-releasing hormone (CRH). Cortisol plays a very important role in many aspects of the inflammatory response and shock (it increases the effect of catecholamines, increases protein catabolism at the muscular level, has action (together with epinephrine and norepinephrine) on vascular smooth muscle, on lipolysis and on neoglycogenesis). But here we try to emphasize that cortisol inhibits the release of "kinins" and that it is closely connected with the release of other mediators and with the systems of coagulation, fibrinolysis and the complement system in the inflammatory response. In addition, cortisol considerably reduces the number of lymphocytes, especially the number of T- lymphocytes, in patients with sepsis. in this regard, it is very noticeable that the majority of patients affected by COVID-19 show lymphopenia. Nitric oxide (NO) is synthesized in the body from L-arginine by an enzyme: nitric oxide synthase. There are two types of this enzyme: one is a constituent of the cytoplasm and is Ca++ and calmodulin dependent for NO release; the other enzyme is also a cytoplasmic component, but is Ca++ independent, however it requires tetrahydro-biopterin and other cofactors for its activation and is inhibited by glucocorticoids. Following the studies of Furchgott and Zawadzki, et al. [47-50] there is no doubt that NO is a very important neurotransmitter. The enzyme nitric oxide synthase is found in brain neurons, but is not present in glia; in the pituitary it is found in brain neurons, but is not present in glia; in the 
pituitary it is found mainly in neurons located in the posterior lobe (which are the neurons that synthesize and release vasopressin and oxytocin), it is also found in the adrenal medulla in neurons that stimulate the cells that release adrenaline or epinephrine), in the intestine it is found in the mesenteric plexuses, regulating peristaltic movements. In addition, nitric oxide synthase is present in numerous tissues, but especially in the cells of the endothelial layer of blood vessels, where it seems to play an important role in vasomotor phenomena, but also as a "messenger" molecule closely connected to the immune system. In all these tissues NO release by nitric oxide synthase appears to be $\mathrm{Ca}^{++}$and calmodulin dependent (as described above), constituting the "physiological NO production pathway".

The point of view that most interests us here is the relationship of NO with the immune response, not only because it is able to stimulate macrophages, endothelial and dendritic cells against bacteria, but also against viruses and rikettsias, and because it is actively involved in the inflammatory process. Its excess production may contribute to a high degree to the pathophysiology of SARS and multiorgan failure. Macrophages produce detectable levels of NO about 6 hours after activation by IFN-g, reaching the maximum level at $24 \mathrm{~h}$. However, there is a "servo-control mechanism" by which NO can regulate its own synthesis, inhibiting IFN-g production from Th1 cells and also that of nitric oxide synthase. In addition, some cytokines, including IL-4 and IL-10 and TGF-b, also have an inhibitory effect (apparently "dose-dependent") on NO production. In this respect, antagonists of cytokine and NO production could be a therapeutic measure in the treatment of COVID-19, as evidenced by some in vitro studies.

\section{Risk Factors Associated with COVID-19 Infection}

Diseases associated with COVID-19 infection, mainly severe heart disease, chronic kidney disease, chronic obstructive pulmonary disease (COPD), cancer (patients undergoing active treatment), immunosuppression due to solid organ transplantation, obesity and type 2 diabetes mellitus, together with advanced age of the patients, can result in "immune dysregulation" leading to failure of the "system regulatory pathway" and "anti-inflammatory pathway" with an exaggerated shift towards the "inflammatory pathway", can result in "immune dysregulation", leading to failure of the "system regulatory pathway" and the "anti-inflammatory pathway" with an exaggerated shift to the "inflammatory pathway" which can develop into a huge release of cytokines and inflammatory factors called "cytokine storm".

Advanced age is perhaps the most important factor in our century, since there are populations of people living in the world at very advanced ages of life (even people > 100 years), especially in developed countries. Overall, published work with respect to patient age shows that the COVID-19 pandemic is causing a large increase in mortality in the elderly population, relative to the mortality rate observed in patients under 70 years of age." The mortality rate is dramatically alarming in the case of patients older than 80 years, about 30\% compared to the total population of COVID-19 infected patients [44]. Some currently published statistical data show that the probability of death from COVID-19, compared with the age group of infected patients aged 18-29 years, can be summarized as follows: persons aged 30-39 years ( 2 times higher), 40-49 years (3 times higher), 50-64 years (4 times higher), and 50-64 years (4 times higher). higher). 65-74 years (5 times higher), 74-84 years ( 8 times higher), > 85 years (13 times higher) [51]. All of the above shows that the COVID-19 pandemic is causing a large increase in mortality in the elderly population, compared to the mortality rate observed in patients younger than 70 years of age. The mortality rate is dramatically alarming in the case of patients over 80 years of age, about $30 \%$ compared to the total population of $\mathrm{CoV}-2$ infected patients.

\section{Important Characteristics of Aging}

Chronic inflammation in aging, described as "inflammatory aging, may occur in elderly patients, and may also be associated with other related disorders. with inflammation: diabetes mellitus, obesity, arthrosis, etc. Consequently, the increased generation of pro-inflammatory markers in "inflammatory aging" may have an impact on the severe inflammatory process that occurs in patients with COVID-19 and increased risk of mortality. Several factors, including altered ACE2 receptor expression, excess reactive oxygen species (ROS) production, senescent adipocyte activity, altered autophagy and mitophagy, "immunosenescence", as well as severe vitamin D deficiency (VD) may be associated with "inflammatory aging" and contribute to the cytokine storm in elderly patients suffering from COVID-19 [52,53].

\section{Alteration Of Ace2 Receptor Expression}

SARS-CoV-2" uses the same receptor "angiotensin-converting enzyme 2" (ACE2) as "SARS-CoV" (the coronavirus associated with the SARS outbreak in 2003). The "renin-angiotensin system" (RAS) is an important regulator of several physiological events, including cardiovascular and blood volume, natriuresis, diabetes, chronic kidney disease and liver fibrosis. The study by Xudong and colleagues in 2006 observed in the rat lung that ACE2 expression is significantly reduced with aging; these authors suggest that ACE2, which is higher in young adults compared to older age groups, may contribute to the prevalence of SARS episodes in this age group. On the other hand, Chen and colleagues, in 2020, found a markedly higher expression of ACE2 in Asian women compared with men; they also found an age-dependent decrease in ACE2 expression, and a highly significant decrease in type II diabetic patients, and 
established a negative correlation between ACE2 expression and death from COVID-19 [54].

\section{Excess Production of Reactive Oxygen Species (ROS)}

The effects of reactive oxygen species (ROS) on cellular metabolism have been well documented in a wide variety of species. These include not only roles in programmed cell death and necrosis, but also positive effects, such as induction of defense genes and mobilization of ion transport systems. It is also frequently implicated in "redox signaling" or "oxidative signaling" functions. In particular, platelets involved in wound repair and blood homeostasis release reactive oxygen species to recruit more platelets to sites of injury. They also provide a link to [immune system] adaptation through white blood cell recruitment. Reactive oxygen species are involved in cellular activity in a variety of inflammatory responses including cardiovascular disease. They may also be involved in cochlear damage induced by elevated sound levels, ototoxicity of drugs such as cisplatin, and in congenital deafness in animals and humans. Redox signaling is also involved in mediating apoptosis or programmed cell death and in ischemic injury. Specific examples are strokes and heart attacks. Garrido, et al. [55] identified that immune cells from prematurely aging mice had lower values of antioxidant defenses and higher values of ROS and pro-inflammatory cytokines, thus suggesting that excessive ROS production during aging may activate the inflammatory response and subsequently increased release of pro-inflammatory cytokines, which include TNF- $\alpha$, IL-1 $\beta$, IL- 2 and IL- 6 and adhesion molecules. Therefore, excessive ROS production and inflammation are closely related, as they are involved in the pathogenesis of chronic inflammation and "inflammatory aging" in older adults.

\section{Autophagy and Age}

Autophagy is a conserved catabolic turnover pathway in eukaryotic cells by which cellular material is delivered to lysosomes for degradation. The autophagy process is related to the maintenance of cellular homeostasis, and its dysregulation could lead to the development of several pathophysiological diseases related to aging [56]. It has been shown that the autophagy process decreases during aging and leads to the accumulation of damaged macromolecules and organelles. Decreased autophagy during aging may also lead to dysfunctions in mitochondria and consequently to increased ROS production [57] (since mitochondria are the main source of ROS. On the other hand, mitophagy, which is characterized by autophagic degradation of mitochondria, decreases in aging the decrease in mitophagy, together with the decrease in antioxidant capacity during aging [58], may increase the levels of ROS in the human organism and also to the increased secretion of proinflammatory cytokines during aging [59-62].

\section{Senescent Adipocytes and Age}

Some studies on aging highlight the importance of adipose tissue inflammation in aged animals by elevated release of IL6, IL-8, IL-1 $\beta$, and TNF- $\alpha$. [63-65] Adipose tissue is a dynamic structure that plays an important role in modulating metabolism and inflammation. It is very likely that adipose tissue dysfunction (e.g., obesity during aging) is associated with chronic inflammation in elderly subjects [66]. The mortality rate of obese elderly patients with COVID-19 is approximately $14 \%$. Covarrubias ,et al. [67] found that during aging senescent cells accumulate significantly in visceral adipose tissue and that "inflammatory cytokines" are found in the supernatant of senescent cells, Alicka et al. in 2020 found that "stem cells" derived from adipose tissue of old horses (older than 5 years) exhibited increased gene expression of pro-inflammatory and miRNA genes (such as IL-8, IL-1 $\beta$, TNF- $\alpha$, miR-203b-5p and miR-16-5p) and markers of apoptosis (such as p21, p53, caspase-3, caspase-9) [68]. Therefore, it is possible that elevated release of pro-inflammatory cytokines by senescing adipocytes carries an elevated risk of the "cytokine storm" in obese elderly patients with COVID-19.

\section{Age and Immunosenescence}

Immunological senescence" is characterized by alterations in both humoral and cell-mediated immune response. Dysregulation of the response severely impacts the pro-inflammatory/antiinflammatory balance when the organism is attacked by an infectious agent. It is known that NK cells and macrophages link the innate and cell-mediated immune systems. Some authors have described an increase in the number of circulating NK cells during aging [69]. One of the important cytokines for the cytotoxic activity of NK cells is IL-2, which increases the killing properties and proliferation of NK cells. In a young healthy individual, IL-2 can induce IFNg secretion by NK cells, but this effect is diminished in the elderly [70]. On the other hand, it has been observed that T cell numbers do not decrease during aging, but the $\mathrm{T}$ cell pool shows significant age-related alterations, including impaired responses to $\mathrm{T}$ cell stimulation by mitogens, an inverted CD4+/CD8+ T cell ratio, a reduced proportion of Th0 cells, and an increased proportion of "memory cells," in animals and humans [71-73]. In addition, aging is associated with overproduction of pro-inflammatory cytokines by $\mathrm{T}$ cells, leading to immune pathology [74]. The proportion of Th17 cells increases during aging, resulting in an "inflammatory aging" state in adults [75]. The "Th17 regulatory" cells have the "pro-inflammatory" phenotype and are in balance with "antiinflammatory Th-reg cells." Both cells are derived from a common precursor: Th0 cells [76]. During aging, the generation of several macrophage-induced factors, including fibroblast growth factor, vascular endothelial growth factor, epithelial growth factor, 
transforming growth factor (TGF $\beta$ ), is reduced. TGF $\beta$ is one of the most important "cytokines" released by "anti-inflammatory regulatory cells". Therefore, it is thought that the fragile and mildly overactive immune system in older adults cannot turn off proinflammatory response in COVID- infection. 19. The clinical findings in severe patients with COVID-19 infection are consistent with the literature mentioned above. In 2019, Schouten et al. identified that the increase in "pro-inflammatory cytokines" during aging also correlated with SARS severity and could explain, at least in part, the difference in COVID-19 severity between young adult patients and elderly patients [77].

\section{Age and Vitamin D Deficiency}

Older adults are at risk for vitamin D deficiency due to several factors, including decreased pre-vitamin D production, poor skin integrity, decreased dietary intake of vitamin D, increased adiposity, obesity, decreased kidney function, as well as less time outdoors [78].Vitamin D deficiency has been linked to various inflammatory diseases related to aging, such as rheumatoid arthritis, asthma, inflammatory bowel disease, multiple sclerosis, cardiovascular disease, hypertension, diabetes mellitus, and cancer [79].

Vitamin D together with the vitamin D receptor (VDR) have an important anti-inflammatory function, acting as "immunomodulators" by decreasing the release by Th1 cells of "proinflammatory cytokines" and increasing the release by Th2 cells of "anti-inflammatory cytokines". Furthermore, vitamin D deficiency in elderly subjects is associated with the pro-inflammatory phenotype of immune cells, which probably increases the risk of "inflammatory aging" in older adults [80], and this chronic inflammatory condition could contribute to the "cytokine storm" in elderly patients with COVID-19. However, patients with renal failure or granulomatous disease are at high risk for side effects and should be excluded from being treated with vitamin D supplementation. Upcoming vitamin D supplementation trials will provide more clarity on the in vivo effects and the opportunities and possible limitations of vitamin $\mathrm{D}$ as an immuno-regulatory agent. In this regard, recent work by Murai, et. al [81] shows that high-dose vitamin D3 shows no significant difference among hospitalized patients with COVID-19, nor does it significantly reduce the length of hospital stay. These findings do not support the use of high- dose vitamin D3 for the treatment of moderate to severe COVID-19.

\section{Influence of Sex}

The higher COVID-19 case fatality rate and greater disease severity in men compared to women are likely due to a combination of behavioral/lifestyle risk factors, prevalence of comorbidities, aging, and underlying biological sex differences. However, the underlying biological sex differences and their effects on COVID-19 outcomes have received less attention. The recent review conducted by Haitao Tu, Vermunt JV et al. of the Mayo Clinic (October 2020) [82] summarizes the available literature regarding proposed molecular and cellular markers in COVID-19 infection, their associations with health outcomes, and any reported modifications by sex.

Biological sex differences characterized by such biomarkers exist within healthy populations and also differ with age- and sex-specific conditions, such as pregnancy and menopause. In the context of COVID-19, descriptive biomarker levels are often reported by sex, but data regarding the effect of patient sex on the relationship between biomarkers and COVID-19 disease severity/outcome are scarce. Such biomarkers may offer plausible explanations for the worse COVID- 19 outcomes observed in men. Larger studies with sex-specific reporting and robust analyses are needed to elucidate how sex modifies the cellular and molecular pathways associated with SARS-CoV-2. This would improve biomarker interpretation and clinical management of patients with COVID-19 by facilitating a personalized medical approach to risk stratification, prevention, and treatment. Several comorbidities, which occur disproportionately in men, likely contribute to worse COVID-19 outcomes, it is thought that perhaps ACE inhibitors are involved or that angiotensin receptor blockers may exert adverse effects on COVID-19. Experimental and epidemiological evidence is conflicting as to whether the use of ACE inhibitors and angiotensin receptor blockers upregulate ACE2 expression and affect susceptibility to infection and/or disease severity. Ongoing randomized clinical trials could inform whether this differs by sex and recommendations on the use of such therapy in patients with COVID-19.

\section{Immunologically}

It appears that women have a stronger immune response overall; however, men are more likely to develop the "cytokine storm associated with poor outcomes against COVID-19. Further research on immuno-modulation by sex hormones, age and $\mathrm{X}$-linked gene expression could help explain the poorer survival of men and identify sex-specific risk factors for SARS-CoV-2 infection and the course, outcome and prognosis of COVID.

\section{Current Treatment of COVID-19}

Despite advances in the deterioration of the COVID-19 patient population, there is no approved drug that has considerable beneficial effects in the medical treatment of COVID-19 patients. Hydroxychloroquine was the first drug of choice for the treatment of the disease, but today it is being rejected because ofits ineffectiveness and because in some cases it has aggravated the condition of the treated patient. At present, umifenovir, remdesivir and favipiravir are thought to be the most promising antiviral agents for improving the health of infected patients. Dexamethasone is being considered as the first known steroid drug that can save the lives of critically ill 
patients, as it was shown in a randomized clinical trial in the UK to reduce the death rate in patients with COVID-19. However, despite its increased use worldwide it is not a truly effective treatment over the current high mortality rate in severe cases.

Based on the evidence, the US Food and Drug Administration (FDA) approved some drugs that had already been used in the treatment of SARC-CoV and MERC-COV. The primary treatment chosen for COVID-19, lopinavir, is an antiretroviral (ARV) drug used for the treatment of HIV-1 and has been used for COVID- 19 in combination with ritonavir (potent anti-HIV drug). Currently, 64 clinical trials are underway with lopinavir-ritonavir along with other drug implications, and most of them are in the early stage of progress. The latest evidence for the management of COVID-19 will be uncovered shortly. No single drug may be superior or inferior, however, the use of a single drug may not be effective enough to control this deadly virus, considering PK and drug metabolism, the use of a combination of antivirals with different mechanisms of action may be more effective [83].

\section{Antiviral Agents Used to Date}

\section{Remdesivir}

Remdesivir (GS-5734) was developed by Gilead Sciences (Foster City, CA, USA). It is an adenosine triphosphate analog and has been used to treat coronavirus and Ebola virus. Remdesivir stops viral replication by inhibiting essential replication enzymes (RNA-dependent RNA polymerase). Currently, more than 24 clinical trials are underway in patients with COVID-19 [84].

\section{Favipiravir}

Favipiravir directly inhibits viral transcription by inhibiting RNA polymerase. Currently, 18 clinical trials in various stages of development are underway for the treatment of COVID-A Phase 3 clinical trial has recently been initiated in India, and full study results are expected to be published soon. Clearance for the clinical trial phase evaluation for the safety and efficacy of favipiravir in tablet form has been granted to Appili Therapeutics to monitor COVID-19 in long-term care services [85].

\section{Lopinavir/ritonavir}

Lopinavir (Kaletra) is a potent anti-HIV drug used to treat HIV infection in combination with ritonavir. Ritonavir inhibits the pharmacological metabolism of lopinavir to improve PK (half-life) and activity. The Infectious Diseases Society of America (IDSA) recommended ritonavir-boosted combination therapy for HCV patients as first-line therapy. Lopinavir / ritonavir have shown anti-SARS-CoV-2 activity "in vitro" by inhibiting protease in Vero E6 cells [86]. In addition, SARS patients revealed that lopinavirritonavir plays an important role in explaining clinical outcomes and in combination with IFN improved clinical outcomes in some MERS patients [87]. In India, the EMR division has recommended the dosing schedule of this drug combination for the clinical management of COVID-19.

\section{Ribavirin}

Ribavirin is a broad-spectrum antiviral drug developed by Bausch Health Companies (Bridgewater Township, New Jersey, USA). It is a guanosine analog used to treat several viral diseases. It showed a lower risk of death in ARDS (acute respiratory distress syndrome) infection in combination with lopinavir- ritonavir. In recent "in vitro" studies, ribavirin showed high efficacy against COVID-19; however, in other studies rivavirin showed an unexpected adverse effect, which was very detrimental to some patients with SARS. [88-89].

\section{Umifenovir}

Umifenovir, also known as Arbidolâ, is a broad-spectrum antiviral agent developed by the Russian Institute of Chemical and Pharmaceutical Research. Lopinavir-ritonavir and umifenovir were previously used to treat acute SARC-CoV in clinical practice; however, their efficacy remains debated. The clinical safety and efficacy of umifenovir monotherapy were analyzed in patients with COVID-19 and compared with lopinavir-ritonavir therapy. Umifenovir was found to be better than lopinavir-ritonavir for the treatment of COVID-19 [90]. This drug has obtained approval to proceed with the phase III clinical trial of umifenovir. This randomized, double-blind, placebo-controlled trial will test the efficacy, safety and tolerability of umifenovir. Results are expected to be reported soon [83].

\section{Nitazoxanide}

Nitazoxanide inhibits viral infection by potentiating the hostspecific mechanism. Although the "in vitro" activity of nitazoxanide against SARC-CoV-2 suggests that it is effective, more clinical data are needed to estimate efficacy and safety against CO-VID-19 [91]. Currently, many clinical trials of nitazoxanide are underway with various doses to treat patients with COVID-19. 969Although the results are not encouraging or available yet, the FDA has given approval to Azidus Brazil for nitazoxanide to continue with the Phase II clinical trial.

\section{Ivermectin}

Ivermectin, an FDA-approved antiparasitic agent as effective as Albendazoleâ, has shown activity against many viruses. Recently, an in vitro study has shown that ivermectin inhibits COVID-19 replication. Its antiviral activity may play a key role and be a potential candidate to treat COVID-19. Finally, the FDA announced a statement for the administration of ivermectin in patients with COVID-19 [92]. 


\section{Interferons}

Interferon (IFN) is a broad-spectrum antiviral agent that inhibits viral replication by interacting with the toll-like receptor (TLR Type III IFNs (IFN- $\lambda s$ ) were identified in 2003 and were independently used to elicit antiviral resistances in cells. One member of this family (IFN- $\lambda$ ) [93] was shown to be effective in 2013. IFNs of this type have been used to treat patients critically ill with chronic hepatitis $\mathrm{C}$ virus and have also been effective in treating people infected with hepatitis B virus, so they are believed to have the ability to protect patients during outbreaks of other viruses. IFN- $\lambda$ has also been shown to be more efficacious compared to IFN $\alpha$-based therapies, also leading to less increase in inflammation and tissue damage, and potentially restricted viral spread from the nasal epithelium to the upper respiratory tract. Moreover, IFN $\alpha$ and $\beta$ exhibited activity against SARS-CoV "in vitro". IFN $\beta$ also showed potential action to decrease MERS-CoV replication. For the most part, type I IFN showed a rapid decrease in viral load in patients with mild or moderate COVID-19. In severe COVID- 19 infection, IFN showed an antiviral response, but with elevated pulmonary cytokine levels, and weakened T-cell response and acute clinical relapse [94].

\section{Dexamethasone}

The main synthetic glucocorticoids: dexamethasone, triancinolone and prednisone are used as immunosuppressants, but their therapeutic indications also include their anti-inflammatory action, and because of their qualities as anti-lymphocyte cytostatics they are used in oncology and in the treatment of allergic diseases. The immunological effects of these drugs are multiple and differ between experimental animals (rodents) and man. In man there is, within a few hours of administration, an increase in neutrophils and a decrease in all other white blood cells in peripheral blood, this decrease being more pronounced for $\mathrm{B}$ and $\mathrm{T}$ lymphocytes. Although a single dose of glucocorticoids has little effect on B lymphocytes, treatment for several days (3 to 10) may result in a decrease in IgG, IgA and IgM. The FDA approved dexamethasone as a spectrum immunosuppressant in 1958. It is 30 times more potent and longer lasting than cortisone and reduces the ability of B cells to synthesize antibodies [95]. However, a clinical trial showed that dexamethasone saved the lives of severely ill COVID-19-infected patients in the United Kingdom [96]. The UK government declared that dexamethasone was allowed as an immediate treatment option for hospitalized patients who were critically ill and on ventilators. WHO added dexamethasone to the list of life-saving drugs that are readily available at low cost. In the U.S., guidance was issued to recommend dexamethasone as a treatment option for patients infected with CO- VID-19. However, clinical evidence does not support the use of corticosteroids in COVID-19 infection [96]. Dexamethasone may regulate, to some extent, the damaging effects of cytokines by limiting their release, but it has not been shown to be able to inhibit the "cytokine storm", when the antigen overwhelms the regulatory capacity of the immune response. In addition, dexamethasone prevents macrophages and NK cells from eliminating nosocomial pathogens associated with "coronavirus".

\section{Tetracyclines}

Tetracycline can be used as a possible treatment option for patients with COVID-19 because of its known activity to decrease the level of inflammatory cytokines such as IL-1b and IL-6 [97]. Both IL-1b and IL-6 levels increase significantly in the body of patients during COVID-19 infection. Tetracycline has also been shown to decrease inflammatory factors in the circulation through activation of protein kinase $\mathrm{C}$ and induction of programmed cell death [98].

\section{Tocilizumab}

Tocilizumab (called Actemra ${ }^{\circledR}$ ) is a recombinant monoclonal antibody developed by Roche Pharmaceuticals (Basel, Switzerland). Tocilizumab is basically used to treat rheumatoid arthritis. It was designed as an IL-6 receptor blocker to inhibit the binding of IL-6 to its receptor, thus alleviating the "cytokine release" syndrome.

IL-6 is significantly increased in the body of patients when exposed to COVID-19 infection. This is why tocilizumab is used as a therapeutic option for the treatment of patients with COVID-19 [99]. In COVID- 19 infected patients, $\mathrm{T}$ lymphocytes and macrophages produce IL-6 and and help the "cytokine storm" and severe inflammatory responses in the lungs and other tissues. Tocilizumab has binding affinity for the IL- 6 receptor and renders the receptor unable to bind IL-6, decreasing the inflammatory response and ultimately decreasing the IL-6 signal transduction pathway [100]. Consequently, it may be essentially an effective therapeutic drug for the treatment of patients with severe COVID-19 infection [101]. The FDA has given Genentech approval to proceed with the Phase III clinical trial of intravenous tocilizumab to evaluate its safety and efficacy in adult patients infected with COVID- 19.

\section{Itolizumab}

Itolizumab (called Alzumab ${ }^{\circledR}$ ) is a recombinant monoclonal antibody against CD6 (IgG1 (Immunoglobulin G1) differentiation group. It was developed for the treatment of psoriatic patients [102]. It showed reduction of IL-6 in critically ill patients. Itolizumab has been shown to have the effect of regulating downstream activation pathways and reduction of inflammatory cytokines, such as IFN- $\gamma$, TNF- $\alpha$ and IL-6 [103]. Based on the mode of action, it could be used as a treatment option for COVID-19 infection [103].

\section{Teicoplanin}

Teicoplanin (called Targocid®) was developed by Sanofi Pharmaceuticals (Paris, France). It is an antiviral drug that can inhibit replication and transcription of the competent virus. It also works against MERS and SARS [104]. Mechanistic investigations 
revealed that teicoplanin specifically inhibits the activity of host cell cathepsin $\mathrm{L}$ and cathepsin B; these proteins are responsible for cleaving the viral glycoprotein, allowing contact of the receptorbinding domain of its core genome and subsequent release into the host cell cytoplasm [105-106]. Since COVID-19 is also "virusdependent" on cathepsin $\mathrm{L}$, some studies suggested that teicoplanin could be used as a therapeutic option to treat COVID-19. According to Ceccarelli, et al. [107], teicoplanin would have a possible therapeutic effect in COVID-19 infected subjects. At present, an in vivo study using teicoplanin in subjects affected by COVID-19 has already been performed for the first time and the results seem quite acceptable compared to a previous report from the same geographical area. Teicoplanin is now thought to be a promising option for the treatment of COVID-19 although more safety data in humans are still required.

\section{Meplazumab}

Meplazumab is a humanized monoclonal antibody that acts against the CD147 spike protein. In in vitro studies, it has been shown to effectively inhibit virus replication in Vero E6 cells [108]. Based on this evidence, a study has been conducted to determine the clinical outcomes with the use of meplazumab in treating patients infected with COVID-19. Meplazumab was previously reported to exhibit activity against "Chauge-Strauss syndrome" (characterized by eosinophilic vasculitis, pulmonary infiltration, sinusitis, neuropathy and asthma) [109].

The Phase I clinical trial (NCT0436369586) in healthy volunteers with maplazumab injection is currently being completed to find the safety, efficacy, tolerability, pharmacokinetic characteristics and dosing regimen for the Phase II clinical trial. In the U.S., an openlabel Phase I and Phase II clinical trial is underway to determine the safety and efficacy of meplazumab injection in patients infected with COVID- 19 (NCT04275245). Meplazumab could be used as a therapeutic option to treat patients with COVID-19.

\section{Eculizumab}

Eculizumab (Soliris ${ }^{\circledR}$, Alexion Pharma International, Zürich, Switzerland), a human monoclonal antibody, is a highly selective and effective C5-binding protein of the complement system with high affinity. It prevents cleavage to $\mathrm{C} 5 \mathrm{a}$ and $\mathrm{C} 5 \mathrm{~b}$ and inhibits the production of the membrane attack complex (MAC) $\mathrm{C} 5 \mathrm{~b}$ 9 to lyse cells. Interestingly, blockade of C5 reveals an indirect "immunoprotective" action by preserving early components of the complement system [110]. Consequently, eculizumab could function as an emergency therapy to treat patients with CO-VID-19 associated with SARS. Some studies have supported the use of eculizumab as a treatment for severe COVID-19. In addition, more clinical trials are approved, some already completed, studying the action of eculizumab in combination with ruxolitinib for efficacy in patients with severe COVID-19 [111].

\section{AMY101}

AMY101 is a highly selective inhibitor of the C3 fraction of the complement system that was developed by Amyndas Pharmaceuticals). AMY101 has successfully completed clinical phase I with acceptable safety and tolerability and is now in phase II clinical trial (NCT04395456) AMY101 could be a unique therapeutic option to overcome the complement-mediated inflammatory response in patients with COVID-19 [112-113].

\section{ARDS-003}

Cannabinoid (CBD) is also a potential treatment for patients with severe COVID-19. It was designed as an injectable form to treat a severe case of coronavirus with "acute respiratory distress syndrome" It may have the advantage of affecting several proinflammatory signaling pathways by enhancing the effectiveness of the drug to rapidly dampen cytokine release and prevent acute ARDS outcomes [114]. The cannabinoid drug named "ARDS-003" has been approved for a Phase I clinical trial, which is still being conducted by Tetra Bio-Pharma. Initially, the FDA emphasized that the results of the non-clinical studies were appropriate to begin the study in COVID-19 infected patients.

\section{LCB1}

CB1 has been shown to be the "SARS-CoV-2 neutralizing antibody". It is a computer-engineered mini- protein that has been synthesized by researchers at the University of Washington School of Medicine. It binds tightly to SARS-CoV-2 spike proteins and prevents it from infecting cells. "LCB1" was shown to protect "Vero E6" cells from SARS-CoV-2 infection. Synthetic antiviral candidates were designed to stop infection by interfering with the mechanism used by the coronavirus to penetrate and enter cells. LCB1 is currently being evaluated in rodents [115]. These "hyperstable mini-agglutinants" provide a starting point for the most novel COVID-19) therapeutics.

\section{Convalescent plasma}

Convalescent plasma therapy has potential to cure COVID-19 (145). Clinical data are very limited to date, but suggest that it is safe, clinically effective, and reduces mortality. However, there is an urgent need for "multicenter clinical trial" studies to establish its efficacy in patients with COVID-19. The U.S. FDA has issued an "emergency use" clearance for "convalescent plasma", currently under investigation, for the treatment of patients with COVID-19. In addition, polyclonal antibodies from convalescent individuals and immunoglobulin concentrates (human and bovine) may also be of interest in the treatment of COVID-19, at this moment a Spanish company is working on it. 


\section{Vaccine development}

Coronaviruses are a family of single-stranded RNA viruses that infect many animal species, including bats and humans. Prior to 2003, only twelve animal or human coronaviruses were identified. In the last eighteen years, three new and deadly strains have spread to humans. In 2003, the severe acute respiratory syndrome coronavirus (SARS-CoV) had an official number of 8096 cases and 774 deaths, with people with pre- existing conditions suffering the highest mortality. The overall effect of COVID-19 vaccine development has been a massive invigoration of the field of pandemic vaccine development. The current vaccines are realizing the theoretical promise of antigen sequence-only platforms, such as mRNA and vector-based platforms, and have massively accelerated their development toward rapid "Phase 3 vaccination against COVID-19" evaluation in a timeframe never seen before for vaccines. However, it is important to note that, despite their rapid manufacturing timeline, these platforms encode an antigen that was developed over a timeline of many years through basic research on coronavirus biology and protein engineering. Largescale investment and unprecedented mobilization of the research community have generated insights into the design, manufacture, formulation, and deployment of candidate vaccines that may pay dividends in the future when society must cope with the next inevitable infectious disease outbreak [116-117,83].

\section{Herbal Medicines}

In China, during the COVID-19 outbreak, some traditional medicines were used, such as Astragali Radix (Huangqi), Saposhnikoviae Radix (Fangfeng), Glycyrrhizae Radix et Rhizoma (Gancao), Atractylodis Macrocephalae Rhizoma (Baizhu) [118]. Some cannabinoid products were also used [119]. As a treatment option to control the inflammatory response medicinal plants with proven antiviral effects and related beneficial effects could be considered as an alternative approach to prevent high-risk population from COVID-19. However, there are no randomized studies to know the true efficacy and side effects of these natural products obtained from plants. Currently, other researchers, and ourselves, are focusing our attention on the acute and systemic inflammatory process that leads to the activation of "damageassociated molecular patterns" (DAMPs), as well as the study of substances capable of preventing or decreasing cell damage by "suppressing/inhibiting DAMPs" (SAMPs), leading to the resolution of the "inflammatory disease".

Authors such as Land WG (Laboratory of Excellence Transplantex, University of Strasbourg, Strasbourg, France and German Academy for Transplantation Medicine), think that current or future therapeutics will include the inhibition of "DAMPs" in hyper-inflammatory processes, e.g., "systemic inflammatory response syndrome" (SIRS), which is currently observed in Covid-19, as well as the application of "SAMPs" in chronic inflammatory diseases, in "hyperresolution" processes, systemic inflammatory response syndrome" (SIRS), currently observed in Covid-19, as well as the application of "SAMPs" in chronic inflammatory diseases, in "hyper-resolving" processes (e.g. compensatory anti-inflammatory response syndrome) and in the administration of "SAMPs" in the treatment of chronic inflammatory diseases. We are in full agreement with this author that controlled production of "DAMPs" and "SAMPs" is necessary to achieve complete homeostatic restoration and repair of tissue injury and tissue damage. On the other hand, we fully agree with this author that a controlled production of "DAMPs" and "SAMPs" is necessary to achieve complete homeostatic restoration and repair of tissue injury, and also with the need to identify and define "a priori" a context-dependent "homeostatic DAMPs/ SAMPs ratio" in each case and a "homeostatic window" of DAMP, and SAMP concentrations, to ensure a safe treatment modality in patients [120]. In this aspect, our research group has recently published the work: "Implant of mesenchymal cells decreases acute cellular rejection in small bowel transplantation"[121] in which the inhibition of acute cell-mediated rejection is observed in an experimental model of allogeneic small intestine transplantation, through the implantation of mesenchymal cells and the activation of the "immune-regulatory response", with an increase in the percentage of Treg cells, a significant increase in TGFb-1 and a decrease in IL-17. This finding will serve as the basis for the project: "Treatment of coronavirus-19 infection using nonsteroidal immunomodulators", where the DAMPs will be the proinflammatory cytokines and the SAMPs will be the "anti-IL17" and "TGF- $\beta 1$ " molecules.

\section{TGF- $\beta 1$}

As we have described above, the "pathway of regulation of the immune response" exerts its role by responding to the needs of the immune response, at a given moment, against the corresponding antigen, increasing the inflammatory activity of the Th1 pathway, mainly by means of Th17 cells and IL-17A, or increasing the antiinflammatory activity of the Th2 pathway, mainly by means of the "transforming growth factor $\beta$ " (TGF- $\beta$ ). In the scheme shown on page 7 of this paper, we can see that this factor already acts from the "immune-regulatory pathway" and is part of the "anti-inflammatory pathway", tipping the balance towards this second pathway. In our previously cited work on the inhibition of acute cell-mediated rejection in intestinal transplantation, "TGFb-1" is shown to be the most important factor, in relation to the other cytokines studied, acting as an inhibitor of the inflammatory immune response in rejection. In 2000, the Canadian researchers Prud'homme GJ and Piccirillo CA already pointed out that the importance of the factor "TGF- $\beta$ " in "immuno-regulation" and tolerance had been recognized once again [122]. 
Like us, the authors propose that there are regulatory T-cell (T-reg) populations, some called T-helper type 3 (Th3), exert their action mainly by secreting this cytokine, and furthermore these authors emphasize the following concepts: 1 ) TGF- $\beta 1$ has multiple suppressive actions on T cells, B cells, macrophages and other cells, and increased TGF- $\beta 1$ production correlates with protection and/ or recovery from autoimmune diseases; 2$)$ TGF- $\beta 1$ and CTLA-4 are molecules that work together to terminate immune responses; 3) Th0, Th1 and Th2 clones can secrete TGF- $\beta 1$ following CTLA-4 cross-linking; 4) TGF- $\beta 1$ may play a role in the switch from effector T cells to memory T cells; 5 ) TGF- $\beta 1$ acts with some other inhibitory molecules to maintain a state of tolerance, which is most evident in immunologically privileged sites, but may also be important in other organs; 6) TGF- $\beta 1$ is produced by many cell types, is always present in plasma (in its latent form) and permeates all organs, binding to matrix components and creating a reservoir of this immunosuppressive molecule; and 7) TGF- $\beta 1$ has beneficial effects in several autoimmune diseases and shows that it can be effectively administered by a somatic gene therapy approach, resulting in depressed inflammatory cytokine production and increased production of endogenous regulatory cytokines.

Currently, March 2021, Aydemir MN, et al. [123] have published an interesting paper. The authors believe that despite the information obtained on the structure of the SARS-CoV-2 viral genome, many aspects of virus-host interactions during infection are still unknown; their purpose in this study has been to identify the "microRNAs" ("miRNAs") encoded by SARS-CoV- 2" and their cellular targets. The authors have employed for this purpose a computational method to predict SARS-CoV-2-encoded miRNAs along with their putative targets in humans. The predicted miRNA targets were grouped into clusters according to their biological processes, molecular function and cellular compartments. Aydemir MN, et al. note that the "TGF- $\beta 1$ pathway" has important functions in many cellular processes, and that it is often manipulated by viruses, as it is a simple pathway. The authors expose that proteins that play a crucial role in almost all steps of this pathway are targeted by SARS-CoV-2 miRNAs and demonstrate that the SARS-CoV "nucleocapsid protein" ("N") inhibits the formation of the "SMAD" complex (family of inducing genes of this pathway), resulting in blocking TGF- $\beta 1$-induced apoptosis of Cov-2-infected cells and, conversely, tissue fibrosis in SARS-CoV-infected "host cells" [124]. Finally, these authors performed an integrative pathway network analysis with target genes and identified 40 SARS-CoV-2 miRNAs and their regulated targets, the analysis shows that the targeted genes including NFKB1, NFKBIE, JAK1-2, STAT3-4, STAT5B, STAT6, SOCS1-6, IL2, IL8, IL10, IL17, TGFBR1-2, SMAD2-4, HDAC1-6 and JARID1A-C , JARID2 plays an important role in NFKB, JAK/STAT and TGFB signaling pathways as well as epigenetic regulatory pathways in cells and they believe that their results may help to understand the virus-host interaction and the role of viral miRNAs during SARS-CoV-2 infection. Since there is currently no drug or effective treatment available for COVID19, it may also help to develop new treatment strategies.

\section{Monoclonal Antibody Against Il-17}

COVID-19 is caused by SARS-CoV-2, a "beta-coronavirus" closely related to MERS-CoV and SARS- CoV, the causative agents of "Middle East respiratory syndrome (MERS)" and "severe acute respiratory syndrome" (SARS), respectively. COVID-19 appears to follow a similar pattern, with $81 \%$ of fatal cases diagnosed with SARS (2). In consideration of this, a recent publication in The Lancet [125] suggests that all patients with COVID-19 should be evaluated for "hyper-inflammation" in order to identify those who would benefit from targeted immunosuppression or immunomodulation to prevent acute lung disease. ("ALI") (acute lung injury) [126]. IL-17 (formally IL-17A) is the best known member of a family of multifunctional cytokines. Its predominant role seems to depend on where the cytokine is expressed (gut, lung or skin) and what the trigger is. These two factors appear to influence whether the predominant effect of its expression is protective or whether it leads to a detrimental hyper-inflammatory state. For MERS-CoV, SARS-CoV and SARS-CoV-2, disease severity was shown to correlate positively with levels of IL-17 and other T helper 17 (Th17) cellrelated pro-inflammatory cytokines, such as IL-1, IL-6, IL-15, TNF and IFN $\gamma$. (see page 7 of this paper) Increased IL-17 levels in LPS-induced "ALI" ("acute lung injury") mice correlated with increased lung injury scores, increased protein-rich inflammatory lung infiltration and decreased overall survival. Furthermore, the addition of exogenous IL- 17 further exacerbated LPS-induced production of TNF, IL-1 $\beta$, IL- 6 and CXCL2, revealing the role of IL17 as a key principal modulator of the inflammatory pathway. In the same study, mice genetically deficient in IL-17 or those that received anti-IL-17 antibodies demonstrated improved survival, less pulmonary infiltration, and improved lung pathology scores after LPS exposure [127] Taken together, analyses of patients with coronavirus-induced lung disease suggest that IL-17 may serve as a biomarker ("DAMP") of disease severity and a potential target for therapy to mitigate SARS-CoV-2 damage, particularly in the lung. Of note, COVID-19 mortality is also associated with myocarditis in the context of SARS.

Zhao Y, et al. [128] in a very recent paper (February 2021) propose a model to understand the underlying mechanisms involved in lung pathology by investigating the role of the lungspecific immune response. The authors obtain immune cells in bronchoalveolar lavage fluid and in blood drawn from patients with COVID-19 with severe disease and patients with bacterial pneumonia not associated with viral infection. By tracing T-cell clones across tissues, they identify Th17 cells similar to clonally 
expanded "memory T cells" resident in lung tissue, which they term "Trm17 cells" and which reside in the lungs even after viral clearance. Analysis of the lung suggests that Trm17 cells may interact with lung macrophages and Tc/s (CD8+ cytotoxic) cells, and is associated with disease severity and lung damage. Ultimately, elevated serum IL-17A and GM-CSF protein levels in patients with COVID- 19 are associated with a more severe clinical course. Zhao Y, et al. suggest that lung Trm17 cells are a potential orchestrator of hyperinflammation in severe COVID-19. On the other hand, Trm17 cells become activated or reactivated as part of the ongoing cytokine storm, during which they may begin to produce pro-inflammatory cytokines such as GM-CSF. This could lead to increased activation of macrophages and cytotoxic CD8+ cells, which other authors have linked to disease severity and ultimately mediate lethal lung damage $[42,45]$.

As related by Zhao Y, et al. To date there have been 2 small pilot studies that have indicated that targeting GM-CSF in patients with severe lung disease by COVID-19 using anti-GM-CSF receptor monoclonal antibodies mavrilimumab or lenzilumab, respectively, may be a strategy to improve clinical outcomes [3,4], although larger controlled clinical trials would be needed to determine the efficacy and biological impact of such approaches. This network of tissue-resident cells may persist in the lungs even after the initiating event, e.g., a viral infection, has been eliminated, contributing to chronic lung pathology. There are three commercially available options: secuquinumab (human monoclonal antibody against IL- 17), ixeki-zumab (humanized monoclonal antibody against IL-17) and brodalumab (human monoclonal antibody against the IL-17 receptor). Both secukinumab and ixekizumab are approved for psoriasis, psoriatic arthritis and ankylosing spondylitis; brodalumab is approved for the treatment of psoriasis alone. All three of these drugs come with warnings about an increased risk of infections. Compared to placebo, clinical trials showed a moderate increase in upper respiratory tract infections ("URIs") for patients treated with secukinumab and a similar number of URIs for patients treated with ixekizumab, while treatment with brodalumab resulted in a lower rate of "URIs." The risk of serious infections is unchanged or low in the short term. Therefore, the use of these drugs in the acute setting of COVID- 19 should not lead to an increased risk of secondary infections.

\section{"NSAIDs" (Non-Steroidal Anti-Inflammatory Drugs)}

Nonsteroidal anti-inflammatory drugs (NSAIDs) are a group of often chemically unrelated compounds that have potent antiinflammatory, analgesic and antipyretic activity and are among the most widely used drugs worldwide. It is generally thought that one of their main mechanisms of action is the inhibition of cyclooxygenase (COX), the enzyme responsible for the biosynthesis of prostaglandins (PGs) and thromboxane. NSAIDs are also associated with an increased risk of gastrointestinal, renal and cardiovascular adverse effects.

The review paper by Bacchi S et al., [129] describes the clinical pharmacology of "NSAIDs, their classification, molecular mechanisms of action and adverse effects, including their possible contribution to "neuro-inflammation" and carcinogenesis, as well as some recent developments aimed at designing effective antiinflammatory agents with improved safety and tolerability profiles. In the late 1980s, it was discovered that COX has two isoforms, each produced by a different gene. The COX-1 gene is located on chromosome 9 and functions as an internal gene that regulates numerous cellular functions, including the complex series of processes responsible for protecting the gastrointestinal mucosa from ulceration. The COX-2 gene, located on chromosome 1, is an early and immediately activated gene and is rapidly deregulated in response to a variety of inflammatory cytokines and cellular injury.

The COX-1 enzyme produces the prostaglandins responsible for gastrointestinal cytoprotection and platelet function, while the COX-2 enzyme produces the reactions responsible for pain perception and inflammation. Thus, COX-1 and CoX-2 enzymes can produce both beneficial and adverse effects due to inhibition of prostanoids, derived from arachidonic acid (AA), which is converted to prostaglandin G2 (PGG2) and H2 (PGH2) as a result of cyclooxygenase (COX) activity, and PGH2 is subsequently metabolized by terminal synthases into biologically active prostanoids. COX-2 expression is greatly restricted under basal conditions, but is greatly increased at inflammatory sites in response to cytokines such as interferon-gTNFa, IL-1, hormones, growth factors, and hypoxia. The pharmacological effects of NSAIDs are due to blockade of COX and consequent reduction of PG synthesis, leading to a decrease in inflammation, pain and fever. The anti-inflammatory action of "NSAIDs" is due to the decrease of vasodilator PGs (PGE2, PGI2), which indirectly reduces edema.

Within the group of non-steroidal anti-inflammatory molecules, the group of pyrazolones stands out and among them metamizole (dipyrone). In 2014, the research group of Jasiecka A et al, [130] published a paper on the pharmacological characteristics of "metamizole": a popular, non-opioid analgesic drug commonly used in human and veterinary medicine. In some cases, this agent is still incorrectly classified as a non-steroidal anti-inflammatory drug. Metamizole is a "pro-drug" that spontaneously breaks down after oral administration into structurally related pyrazolone compounds. In addition to its analgesic effect, the drug is an antipyretic and spasmolytic agent. The mechanism responsible for the analgesic effect is complex and most likely based on inhibition of a central cyclooxygenase- 3 and activation of the opioidergic and cannabinoid systems. Metamizole can block both PG-dependent and PG-independent LPS-induced fever pathways, suggesting that 
this drug has a distinctly different antipyretic action profile than the other NSAIDs. The mechanism responsible for the spasmolytic effect of metamizole is associated with inhibition of intracellular $\mathrm{Ca} 2+$ as a result of reduced inositol phosphate synthesis [130]. Metamizole is predominantly applied in the therapy of pain of different etiology, spastic conditions, especially affecting the digestive tract, and fever refractory to other treatments. Coadministration of morphine and metamizole produces super-additive anti-nociceptive effects [131]. On the other hand, metamizole is a relatively safe pharmaceutical preparation, although it is not completely free of undesirable effects. Among these side effects, the most serious and most controversial is the myelotoxic effect; however, it seems that in the past the risk of metamizole-induced agranulocytosis was exaggerated [132]. Today it is considered that the side effects of metamizole appear only in long periods of treatment of chronic inflammatory diseases. Our research team has studied the effects of "magnesium metamizole" marketed under the name of Nolotilâ and currently produced by Boehringer Laboratories (Germany).

The active ingredient of this drug is the "methylated oxyquinazine" molecule, whose chemical structure is included here: The complete structure of this synthetic drug corresponds to a phenyl-dimethyl pyrazolone derivative whose " $R$ " root is magnesium methylene sulfonate. Its complete formula is dimethyl oxyquinazine methylene methylamine magnesium sulfonate. Since 1975 , we have used this drug in the surgical clinic as an analgesic in the first days of the immediate postoperative period, due to its high analgesic power and also to its anti-adhesiveness and anti-platelet aggregation properties. These findings were obtained in "in vivo" and "in vitro" studies carried out by our research team in the 70's of the last century. [132-134]. Our results have now been ratified by Pfrepper C et al. in 2019 [135]. It is very important to emphasize here that increased platelet adhesiveness and aggregation leads to initial thrombus formation and eventually to thrombosis. Methylated oxyquinazine by its anti- aggregating and antiadhesive action on platelets may contribute to prevent vascular thrombosis. When "CoV-2 antigens" stimulate macrophages or any other "antigen presenting cell" the "pro- inflammatory" cytokines par excellence are released: IL-1, IL-6, IL-8, IL-15, IL-17, IL-18, TNFs, IFNg and PAF (platelet activating factor) (and source of PF4). Through the release of PAF, the immune response acts on the coagulation and fibrinolytic systems, giving rise to signals that cross and intersect between the immune response and the different systems: coagulation, fibrinolytics, cyanins, arachidonic acid, leukotrienes and thromboxanes, etc. Thus, we believe that methylated oxyquinazine could contribute to inhibit or palliate the immune response overwhelmed by COVID-19 in the most severe stage of Cov-2 disease [42]. (see Figure 2) page 5 of this paper). It has recently been published those vaccines using adenovirus vectors can produce thrombosis by activation of PAF and PF4, resulting in increased platelet aggregation and adhesiveness accompanied by thrombocytopenia [136-143]. In this aspect, methylated oxyquinazine (metamizole) could also serve as a prophylaxis of thrombus formation when these vaccines are given (Figure 4).

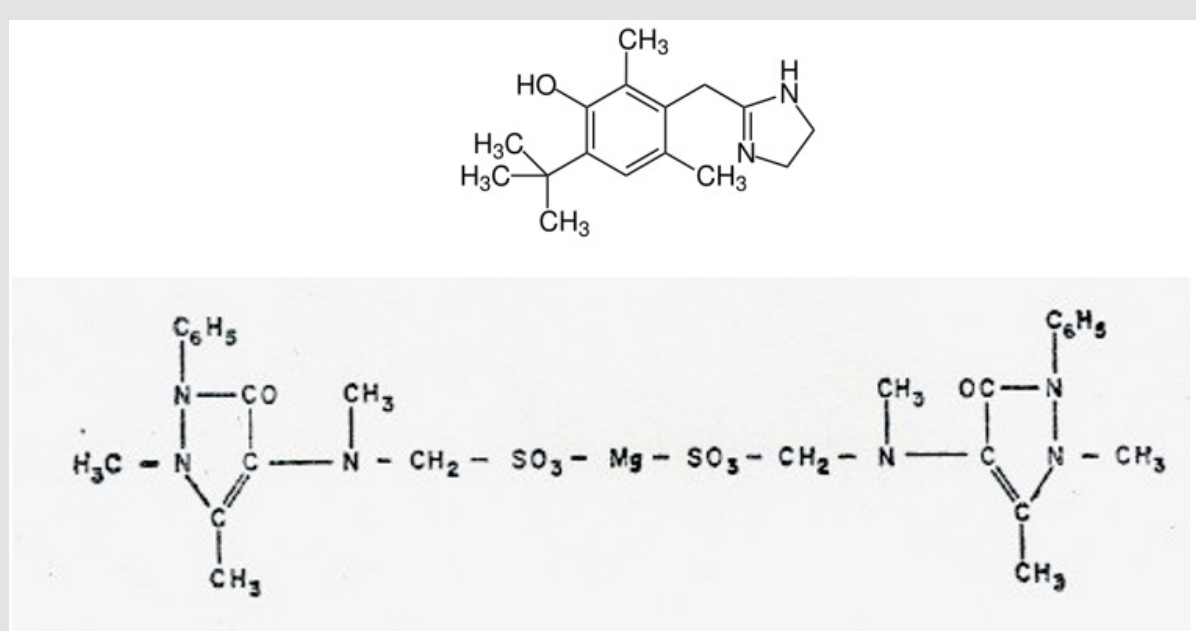

Figure 4: The complete structure of this synthetic drug corresponds to a phenyl-dimethyl pyrazolone derivative whose " $R$ " root is magnesium methylene sulfonate. Its complete formula is: dimethyl oxyquinazine methylene methylamine magnesium sulfonate [134-136].

Our research project is aimed at avoiding the "cytokine storm" by means of molecules that do not inhibit the response to the virus but can avoid the excessive inflammatory response, by activating the "immuno-regulatory pathway" of the immune system. The treatments applied to date fail when patients, especially the elderly or "immuno-compromised" people (suffering from severe heart disease, chronic kidney disease, chronic obstructive pulmonary disease, cancer - patients undergoing active treatment-, 
immunosuppression by transplantation of solid organs, obesity or type 2 diabetes mellitus, or elderly people who also suffer from any of these diseases, reach the most serious stage of the disease, and their body is not capable of avoiding the "cytokine storm" and the multi-organic failure that leads inexorably to death.

\section{References}

1. Zhong NS, Zheng BJ, Li YM, Poon, Xie ZH, et al. (2003) Epidemiology and cause of severe acute respiratory syndrome (SARS) in Guangdong,People's Republic of China, in February, 2003. Lancet 362(9393): 1353-8.

2. Lee N, Hui D, Wu A, Chan P, Cameron P, et al. (2003) A major outbreak of severe acute respiratory syndrome in Hong Kong. N Engl J Med 348(20): 1986-94.

3. Guan Y, Peiris JS, Zheng B, Poon LL, Chan KH, et al. (2004) Molecular epidemiology of the novel coronavirus that causes severe acute respiratory syndrome. Lancet 363(9403): 99-104.

4. Drosten C, Günther S, Preiser W, Van der Werf S, Brodt HR, et al. (2003) Identification of a novel coronavirus in patients with severe acute respiratory syndrome. N Engl J Med 348(20): 1967-76.

5. Ksiazek TG, Erdman D, Goldsmith CS, Zaki SR, Peret T, et al. (2003) Working Group. A novel coronavirus associated with severe acute respiratory syndrome. N Engl J Med 348(20): 1953-66.

6. Peiris JS, Lai ST, Poon LL, Guan Y, Yam LY, et al. (2003) Coronavirus as a possible cause of severe acute respiratory syndrome. Lancet 361(9366): 1319-25.

7. (2004) WHO. Summary of probably SARS cases with onset of illness from 1 November 2002 to 31 July 2003. WHO.

8. Wang M, Yan M, Xu H, Liang W, Kan B, et al. (2005) SARS-CoV infection in a restaurant from palm civet. Emerg Infect Dis 11(12): 1860-5.

9. Ge XY, Li JL, Yang XL, Chmura AA, Zhu G, et al. (2013) Isolation and characterization of a bat SARS-like coronavirus that uses the ACE2 receptor. Nature 503(7477): 535-8.

10. Menachery VD, Yount BL Jr, Debbink K, Agnihothram S, Gralinski LE, et al. (2015) A SARS-like cluster of circulating bat coronaviruses shows potential for human emergence. Nat Med 21(12): 1508-13.

11. Zaki AM, Van Boheemen S, Bestebroer TM, Osterhaus AD, Fouchier RA (2012) Isolation of a novel coronavirus from a man with pneumonia in Saudi Arabia. N Engl J Med 367(19): 1814-19.

12. Hijawi B, Abdallat M, Sayaydeh A, Alqasrawi S, Haddadin A, et al. (2012) Novel coronavirus infections in Jordan, April 2012: epidemiological findings from a retrospective investigation. East Mediterr Health J 19(1): S12-8.

13. Wise J (2012) Patient with new strain of coronavirus is treated in intensive care at London hospital. BMJ 345: e6455.

14. (2015) Korea Centers for Disease Control and Prevention. Middle East Respiratory Syndrome Coronavirus Outbreak in the Republic of Korea. Osong Public Health Res Perspect 6(4): 269-278.

15. (2016) WHO Coronavirus infections: disease outbreak news. WHO.

16. De Wit E, Van Doremalen N, Falzarano D, Munster VJ (2016) SARS and MERS: recent insights into emerging coronaviruses. Nat Rev Microbiol 14(8): 523-34.

17. Reusken CB, Haagmans BL, Müller MA, Gutierrez C, Godeke GJ, et al. (2013) Middle East respiratory syndrome coronavirus neutralising serum antibodies in dromedary camels: a comparative serological study. Lancet Infect Dis 13(10): 859-66.
18. Guan Y, Zheng BJ, He YQ, Liu XL, Zhuang ZX, et al. (2003) Isolation and characterization of viruses related to the SARS coronavirus from animals in southern China. Science 302(5643): 276-8.

19. Wang LF, Shi Z, Zhang S, Field H, Daszak P, et al. (2006) Review of bats and SARS. Emerg Infect Dis 12(12): 1834-40.

20. Reusken CB, Haagmans BL, Müller MA, Gutierrez C, Godeke GJ, et al. (2013) Middle East respiratory syndrome coronavirus neutralising serum antibodies in dromedary camels: a comparative serological study. Lancet Infect Dis 13(10): 859-66.

21. Haagmans BL, Al Dhahiry SH, Reusken CB, Raj VS, Galiano M, et al. (2014) Middle East respiratory syndrome coronavirus in dromedary camels: an outbreak investigation. Lancet Infect Dis 14(2): 140-5.

22. Azhar EI, El-Kafrawy SA, Farraj SA, Hassan AM, Al-Saeed MS, et al. (2014) Evidence for camel-to-human transmission of MERS coronavirus. N Engl J Med 370(26): 2499-505.

23. Raj VS, Farag EA, Reusken CB, Lamers MM, Pas SD, et al. (2014) Isolation of MERS coronavirus from a dromedary camel, Qatar, 2014. Emerg Infect Dis 20(8): 1339-42.

24. Sabir JS, Lam TT, Ahmed MM, Li L, Shen Y, et al. (2016) Co-circulation of three camel coronavirus species and recombination of MERS-CoVs in Saudi Arabia. Science 351(6268): 81-4.

25. Chowell G, Abdirizak F, Lee S, Lee J, Jung E, et al. (2015) Transmission characteristics of MERS and SARS in the healthcare setting: a comparative study. BMC Med 13: 210.

26. Hunter JC, Nguyen D, Aden B, Al Bandar Z, Al Dhaheri W, et al. (2016) Transmission of Middle East Respiratory Syndrome Coronavirus Infections in Healthcare Settings, Abu Dhabi. Emerg Infect Dis 22(4): 647-56.

27. Anderson RM, Fraser C, Ghani AC, Donnelly CA, Riley S, et al. (2004) Epidemiology, transmission dynamics and control of SARS: the 20022003 epidemic. Philos Trans R Soc Lond B Biol Sci 359(1447): 1091-105.

28. Cowling BJ, Park M, Fang VJ, Wu P, Leung GM, et al. (2015) Preliminary epidemiological assessment of MERS-CoV outbreak in South Korea, May to June 2015. Euro Surveill 20(25): 7-13.

29. Peiris JS, Chu CM, Cheng VC, Chan KS, Hung IF, et al. (2003) Clinical progression, and viral load in a community outbreak of coronavirusassociated SARS pneumonia: a prospective study. Lancet 361(9371): 1767-72.

30. Bin SY, Heo JY, Song MS, Lee J, Kim EH, et al. (2016) Environmental Contamination and Viral Shedding in MERS Patients During MERS-CoV Outbreak in South Korea. Clin Infect Dis 62(6): 755-60.

31. Kucharski AJ, Althaus CL (2015) The role of superspreading in Middle East respiratory syndrome coronavirus (MERS-CoV) transmission. Euro Surveill 20(25): 14-8.

32. Oh MD, Choe PG, Oh HS, Park WB, Lee SM, et al. (2015) Middle East Respiratory Syndrome Coronavirus Superspreading Event Involving 81 Persons, Korea 2015. J Korean Med Sci 30(11): 1701-5.

33. Wong G, Liu W, Liu Y, Zhou B, Bi Y, et al. (2015) MERS, SARS, and Ebola: The Role of Super-Spreaders in Infectious Disease. Cell Host Microbe 18(4): 398-401.

34. Huang C, Wang Y, Li X, Ren L, Zhao J, et al. (2020) Clinical features of patients infected with 2019 novel coronavirus in Wuhan, China. Lancet 395(10223): 497-506.

35. Anon (2020) Seven days in medicine: 8-14 Jan 2020. BMJ 368: m132.

36. Lu R, Zhao X, Li J, Niu P, Yang B, et al. (2020) Genomic characterisation and epidemiology of 2019 novel coronavirus: implications for virus origins and receptor binding. Lancet 395(10224): 565-574. 
37. (2019) European Centre for Disease Prevention and Control. European Centre for Disease Prevention and Control data Geographical distribution of 2019-nCov cases.

38. Zheng J (2020) SARS-CoV-2: An Emerging Coronavirus that Causes a Global Threat. Int J Biol Sci 16(10): 1678-1685.

39. (2019) WHO. Update WHO Report 2020.

40. WHO. Coronavirus Disease 2019 (COVID-19) Situation Report-52. (2019) Geneva: World Health Organization.

41. Navarro M, Salinas JC, Román J, Larrad L, Pastor C, et al. (1992) Immunological response to surgery and implicate cytokines. Eur Surg Res 24 (S2): 58.

42. Navarro-Zorraquino M (1997) Respuesta inmunológica en el shock y el fallo multiorgánico. In: Navarro-Zorraquino M (Edt.)., Aspectos inmunológios de la cirugía. ed. Zaragoza: Prensas Universitarias de Zaragoza, p. 261-300.

43. Navarro-Zorraquino M (2020) Possible Treatment of Seriously Ill Patient with COVID-19, from the Immunological Point of View. J SARSCoV-2 COVID 1: 001.

44. Mortaz E, Tabarsi P, Varahram M, Folkerts G, Adcock IM (2020) The Immune Response and Immunopathology of COVID-19. Front Immunol 11: 2037.

45. Channappanavar R, Perlman S (2017) Pathogenic human coronavirus infections: causes and consequences of cytokine storm and immunopathology. Semin Immunopathol 39(5): 529-539.

46. Li H, Liu L, Zhang D, Xu J, Dai H, et al. (2020) SARS- CoV-2 and viral sepsis: observations and hypotheses. Lancet 395(10235): 1517-1520.

47. Furchgott RF, Zawadzki JV (1980) The obligatory role of endothelial cells in the relaxation of arterial smooth muscle by acetylcholina. Nature (Lond) 288: 373-376.

48. Moncada S, Palmer RM, Higgs EA (1991) Nitirc-oxide: Physiology pathophysiology and pharmacology. Reviews 43(2): 110-142.

49. Bredt DS, Hwang PM, Snyder SH (1990) Localization of oxide synthase indicating a neural role for nitric oxide. Nature (Lond) 347: 768-770.

50. Brenman JE, Bredt DS (1997) Synaptic signaling by nitric oxide. Curr Opin Neurobiol 7(3): 374-8.

51. CDC Coronavirus Disease 2019 (COVID-19) [Internet]. Centers for Disease Control and Prevention. People with Certain Medical Conditions. 2020 [citado 4 de diciembre de 2020].

52. Gholam Hossein Meftahi, Zohreh Jangravi, Hedayat Sahrae, Zahra Bahari (2020) The possible pathophysiology mechanism of cytokine storm in elderly adults with COVID-19 infection: the contribution of "inflameaging" Review Inflamm Res 69(9): 825-839.

53. Chen Y, Klein SL, Garibaldi BT, Li H, Wu C, et al. (2021) Aging in COVID-19: Vulnerability, immunity and intervention. Ageing Res Rev 65: 101205.

54. Chen J, Jiang Q Xia X, Liu K, Yu Z, et al. (2020) Individual variation of the SARS-CoV-2 receptor ACE2 gene expression and regulation. Aging Cell. 19(7): e13168.

55. Xie X, Chen J, Wang X, Zhang F, Liu Y (2006) Age- and gender-related difference of ACE2 expression in rat lung. Life Sci 78(19): 2166-71.

56. Garrido A, Cruces J, Ceprián N, Vara E, De la Fuente M (2019) Oxida- tiveinflammatory stress in immune cells from adult mice with premature aging. Int J Mol Sci 20(3): 769.

57. Barbosa MC, Grosso RA, Fader CM (2019) Hallmarks of Aging: An Autophagic Perspective. Front Endocrinol (Lausanne) 9: 790.
58. Salminen A, Kaarniranta K, Kauppinen A (2012) Inflammaging: disturbed interplay between autophagy and inflammasomes. Aging 4(3): 166.

59. Chen G, Kroemer G, Kepp O (2020) Mitophagy: an emerging role in aging and age-associated diseases. Front Cell Dev Biol 8: 200.

60. Ghobadi N, Sahraei H, Meftahi GH, Bananej M, Salehi S (2016) Effect of estradiol replacement in ovariectomized NMRI mice in response to acute and chronic stress. J Appl Pharm Sci 6(11): 176-84.

61. Faraji N, Shiravi A, Bahari Z, Shirvani H, Meftahi GH (2020) Baso- lateral amygdala a1-adrenergic receptor suppression attenuates stressinduced anxiety-like behavior and spine morphology impairment on hippocampal CA1 pyramidal neurons. Neuro-chem J 14: 77-89.

62. Vernucci E, Tomino C, Molinari F, Limongi D, Aventaggiato M, et al. (2019) Mitophagy and oxidative stress in cancer and aging: focus on sirtuins and nanomaterials. Oxid Med Cell Longev, pp. 1-19.

63. Bahari Z, Meftahi GH, Meftahi MA (2018) Dopamine effects on stressinduced working memory deficits. Behav Pharmacol 29(7): 584-91.

64. Davalos AR, Coppe JP, Campisi J, Desprez PY (2010) Senescent cells as a source of inflammatory factors for tumor progression. Cancer Metastasis Rev 29(2):273-83.

65. Freund A, Orjalo AV, Desprez PY, Campisi J (2010) Inflammatory networks during cellular senescence: causes and consequences. Trends Mol Med 16(5): 238-46.

66. Stout MB, Justice JN, Nicklas BJ, Kirkland JL (2017) Physiological aging: links among adipose tissue dysfunction, diabetes, and frailty. Physiology 32(1): 9-19.

67. Petrakis D, Margină D, Tsarouhas K, Tekos F, Stan M, et al. (2020) Obesity - a risk factor for increased COVID-19 prevalence, severity and lethality (Review). Mol Med Rep 22(1): 9-19.

68. Covarrubias AJ, Kale A, Perrone R, Lopez-Dominguez JA, Pisco AO, et al. (2019) Aging-related inflammation driven by cellular senes-cence enhances NAD consumption via activation of CD38+ pro-inflammatory macrophages. bioRxiv 609438.

69. Alicka M, Kornicka-Garbowska K, Kucharczyk K, Kępska M, Röcken M, et al. (2020) Agedependent impairment of adipose-derived stem cells isolated from horses. Stem Cell Res Ther 11(1): 1-20.

70. Ponnappan S, Ponnappan U (2011) Aging and immune function: molecular mechanisms to interventions. Antioxid Redox Sign 14(8): 1551-1585.

71. Camous X, Pera A, Solana R, Larbi A (2012) NK cells in healthy aging and age-associated diseases. BioMed Res Int 2:1-8.

72. Bektas A, Schurman SH, Sen R, Ferrucci L (2017) Human T cell immunosenescence and inflammation in aging. J Leukocyte Biol 102(4): 977-88.

73. García-Álvarez F, Navarro-Zorraquino M, Castro A, Grasa JM, Pastor C, et al. (2009) Effect of age on cytokine response in an experimental model of osteomyelitis. Biogerontology 10(5): 649-658.

74. García Álvarez F, González P, Navarro-Zorraquino M, Larrad L, GarcíaAlvarez Álvarez I, et al. (2008) Immune cell variations in patients with hip fracture. Archv Gerontol Geriatr 46(2): 117-124.

75. Zanni F, Vescovini R, Biasini C, Fagnoni F, Zanlari L, et al. (2003) Marked increase with age of type 1 cytokines within memory and effector/ cytotoxic CD8+ T cells in humans: a contribution to understand the relationship between inflammation and immunosenescence. Exp Gerontol 38(9): 981-7. 
76. Schmitt V, Rink L, Uciechowski P (2013) The Th17/Treg balance is disturbed during aging. Exp Gerontol 48(12): 1379-86.

77. Cao X (2020) COVID-19: immunopathology and its implications for therapy. Nat Rev Immunol 20: 269-70.

78. Schouten LR, Van Kaam AH, Kohse F, Veltkamp F, Bos LD, et al. (2019) Age-dependent differences in pulmonary host responses in ARDS: a prospective observational cohort study. Ann Intensive Care 9(1): 55.

79. Elizondo Montemayor L, Castillo EC, Rodríguez López C, Villarreal Calderón JR, Gómez Carmona M, et al. (2017) Seasonal variation in vitamin $\mathrm{D}$ in association with age, inflammatory cytokines, anthropometric parameters, and lifestyle factors in older adults. Mediat Inflamm, pp. 1-14.

80. Aslam MM, John P, Bhatti A, Jahangir S, Kamboh MI (2019) Vitamin D as a principal factor in mediating rheumatoid arthritis-derived immune response. BioMed Res Int 2019: 1-12.

81. Sişmanlar T, Aslan AT, Gülbahar Ö, Özkan S (2016) The effect of vitamin $\mathrm{D}$ on lower respiratory tract infections in children. Turk Pediatr Ars 51(2): 94.

82. Murai IH, Fernandes AL, Sales LP, Pinto AJ, Goessler KF, et al. (2021) Effect of a Single High Dose of Vitamin D3 on Hospital Length of Stay in Patients with Moderate to Severe COVID-19: A Randomized Clinical Trial. JAMA 325(11): 1053-1060.

83. Haitao T, Vermunt JV, Abeykoon J, Ghamrawi R, Gunaratne M, et al (2020) COVID-19 and Sex Differences: Mechanisms and Biomarkers. Mayo Clin Proc 95(10): 2189-2203.

84. Trivedi N, Verma A, Kumar D (2020) Possible treatment and strategies for COVID-19: review and assessment. Eur Rev Med Pharmacol Sci 24(23): 12593-12608.

85. De Wit E, Feldmann F, Cronin J, Jordan R, Okumura A, et al. (2020) Prophylactic and therapeutic remdesivir (GS-5734) treatment in the rhesus macaque model of MERS-CoV infection. Proc Natl Acad Sci U S A 117(12): 6771-6776.

86. Cai Q Yang M, Liu D, Chen J, Shu D, et al. (2020) Experimental Treatment with Favipiravir for COVID-19: An Open-Label Control Study. Engineering (Beijing) 6(10): 1192-1198.

87. Choy KT, Wong AY, Kaewpreedee P, Sia SF, Chen D, et al. (2020) Remdesivir, lopinavir, emetine, and homoharringtonine inhibit SARSCoV-2 replication in vitro. Antiviral Res 178: 104786.

88. Yao TT, Qian JD, Zhu WY, Wang Y, Wang GQ (2020) A systematic review of lopinavir therapy for SARS coronavirus and MERS coronavirus-A possible reference for coronavirus disease-19 treatment option. J Med Virol 92(6): 556-563.

89. Wang M, Cao R, Zhang L, Yang X, Liu J, et al. (2020) Remdesivir and chloroquine effectively inhibit the recently emerged novel coronavirus (2019-nCoV) in vitro. Cell Res 30(3): 269-271.

90. Chan JF, Yao Y, Yeung ML, Deng W, Bao L, et al. (2015) Treatment with Lopinavir/Ritonavir or Interferon- $\beta 1 \mathrm{~b}$ Improves Outcome of MERS-CoV Infection in a Nonhuman Primate Model of Common Marmoset. J Infect Dis 212(12): 1904-13.

91. Zhu Z, Lu Z, Xu T, Chen C, Yang G, et al. (2020) Arbidol monotherapy is superior to lopinavir/ritonavir in treating COVID-19. J Infect 81(1): e21-e23.

92. Pepperrell T, Pilkington V, Owen A, Wang J, Hill AM (2020) Review of safety and minimum pricing of nitazoxanide for potential treatment of COVID-19. J Virus Erad 6(2): 52-60.

93. Heidary F, Gharebaghi R (2020) Ivermectin: a systematic review from antiviral effects to COVID-19 complementary regimen. J Antibiot (Tokyo) 73(9): 593-602.
94. Ströher U, DiCaro A, Li Y, Strong JE, Aoki F, et al. (2004) severe acute respiratory syndrome-related coronavirus is inhibited by interferonalpha. J Infect Dis 189(7): 1164-7.

95. Jamilloux Y, Henry T, Belot A, Viel S, Fauter M, et al. (2020) Should we stimulate or suppress immune responses in COVID-19? Cytokine and anti-cytokine interventions. Autoimmun Rev 19(7): 102567.

96. Ledford H (2020) Coronavirus breakthrough: dexamethasone is first drug shown to save lives. Nature 582(7813): 469.

97. Russell CD, Millar JE, Baillie JK (2020) Clinical evidence does not support corticosteroid treatment for 2019-nCoV lung injury. Lancet 395(10223): 473-475.

98. Griffin MO, Fricovsky E, Ceballos G, Villarreal F (2010) Tetracyclines: a pleitropic family of compounds with promising therapeutic properties. Review of the literature. Am J Physiol Cell Physiol 299(3): C539-48.

99. Bharadwaj S, Lee KE, Dwivedi VD, Kang SG (2020) Computational insights into tetracyclines as inhibitors against SARS-CoV-2 Mpro via combinatorial molecular simulation calculations. Life Sci 257: 118080.

100. Luo P, Liu Y, Qiu L, Liu X, Liu D, et al. (2020) Tocilizumab treatment in COVID-19: A single center experience. J Med Virol 92(7): 814-818.

101. Zhang C, Wu Z, Li JW, Zhao H, Wang GQ (2020) Cytokine release syndrome in severe COVID-19: interleukin-6 receptor antagonist tocilizumab may be the key to reduce mortality. Int J Antimicrob Agents 55(5): 105954.

102. Xu X, Han M, Li T, Sun W, Wang D, et al. (2020) Effective treatment of severe COVID-19 patients with tocilizumab. Proc Natl Acad Sci U S A 117(20): 10970-10975.

103. Dogra S, Uprety S, Suresh SH (2017) Itolizumab, a novel anti-CD6 monoclonal antibody: a safe and efficacious biologic agent for management of psoriasis. Expert Opin Biol Ther 17(3): 395-402.

104. Loganathan S, Athalye SN, Joshi SR (2020) Itolizumab, an antiCD6 monoclonal antibody, as a potential treatment for COVID-19 complications. Expert Opin Biol Ther 20(9): 1025-1031.

105. Wang Y, Cui R, Li G, Gao Q Yuan S, et al. (2016) Teicoplanin inhibits Ebola pseudovirus infection in cell culture. Antiviral Res 125: 1-7.

106. Baron SA, Devaux C, Colson P, Raoult D, Rolain JM (2020) Teicoplanin: an alternative drug for the treatment of COVID-19? Int J Antimicrob Agents 55(4): 105944.

107. Zhou N, Pan T, Zhang J, Li Q, Zhang X, et al. (2016) Glycopeptide Antibiotics Potently Inhibit Cathepsin L in the Late Endosome/ Lysosome and Block the Entry of Ebola Virus, Middle East Respiratory Syndrome Coronavirus (MERS-CoV), and Severe Acute Respiratory Syndrome Coronavirus (SARS-CoV). J Biol Chem 291(17): 9218-32.

108. Ceccarelli G, Alessandri F, d'Ettorre G, Borrazzo C, Spagnolello O, et al. (2020) Is teicoplanin a complementary treatment option for COVID-19? The question remains. Int J Antimicrob Agents 56(2): 106029.

109. Wang K, Chen W, Zhang Z, Deng Y, Lian JQ et al. (2020) CD147-spike protein is a novel route for SARS-CoV-2 infection to host cells. Signal Transduct Target Ther 5(1): 283 .

110. Wechsler ME, Akuthota P, Jayne D, Khoury P, Klion A, et al. (2017) Mepolizumab or Placebo for Eosinophilic Granulomatosis with Polyangiitis. N Engl J Med 376(20): 1921-1932.

111. Mastellos DC, Yancopoulou D, Kokkinos P, Huber-Lang M, Hajishengallis G, et al. (2015) Compstatin: a C3-targeted complement inhibitor reaching its prime for bedside intervention. Eur J Clin Invest 45(4): 423-40. 
112. Giudice V, Pagliano P, Vatrella A, Masullo A, Poto S, et al. (2020) Combination of Ruxolitinib and Eculizumab for Treatment of Severe SARS-CoV-2-Related Acute Respiratory Distress Syndrome: A Controlled Study. Front Pharmacol 11: 857.

113. Silasi-Mansat R, Zhu H, Georgescu C, Popescu N, Keshari RS, et al. (2015) Complement inhibition decreases early fibrogenic events in the lung of septic baboons. J Cell Mol Med 19(11): 2549-63.

114. Mastaglio S, Ruggeri A, Risitano AM, Angelillo P, Yancopoulou D, et al (2020) The first case of COVID-19 treated with the complement C3 inhibitor AMY-101. Clin Immunol 215:108450.

115. Costiniuk CT, Jenabian MA (2020) Acute inflammation and pathogenesis of SARS-CoV-2 infection: Cannabidiol as a potential antiinflammatory treatment? Cytokine Growth Factor Rev 53:63-65.

116. Cao L, Goreshnik I, Coventry B, Case JB, Miller L, et al. (2020) De novo design of picomolar SARS-CoV-2 miniprotein inhibitors. Science 370(6515): 426-431.

117. Salazar E, Perez KK, Ashraf M, Chen J, Castillo B, et al. (2020) Treatment of Coronavirus Disease 2019 (COVID-19) Patients with Convalescent Plasma. Am J Pathol 190(8): 1680-1690.

118. Hodgson SH, Mansatta K, Mallett G, Harris V, Emary KRW, et al (2021) What defines an efficacious COVID-19 vaccine? A review of the challenges assessing the clinical efficacy of vaccines against SARS CoV-2. Lancet Infect Dis 21(2): e26-e35.

119. Mullard A (2020) COVID-19 vaccine development pipeline gears up. Lancet 395(10239): 1751-1752.

120. Luo H, Tang QL, Shang YX, Liang SB, Yang M, et al. (2020) Can Chinese Medicine Be Used for Prevention of Corona Virus Disease 2019 (COVID-19)? A Review of Historical Classics, Research Evidence and Current Prevention Programs. Chin J Integr Med 26(4): 243-250.

121. Tahamtan A, Tavakoli-Yaraki M, Salimi V (2020) Opioids/cannabinoids as a potential therapeutic approach in COVID-19 patients. Expert Rev Respir Med 14(10): 965-967.

122. Land WG (2020) Use of DAMPs and SAMPs as Therapeutic Targets or Therapeutics: A Note of Caution. Mol Diagn Ther 24(3): 251-262.

123. Navarro-Zorraquino M, Pastor C, Stringa P, Soria J, Hernández F, et al. (2020) Implant of mesenchymal cells decreases acute cellular rejection in small bowel transplantation. Cir Cir 88(5): 554-561.

124. Prud'homme GJ, Piccirillo CA (2000) The inhibitory effects of transforming growth factor-beta-1 (TGF-beta1) in autoimmune diseases. J Autoimmun 14(1): 23-42.

125. Aydemir MN, Aydemir HB, Korkmaz EM, Budak M, Cekin N, et al. (2021) Computationally predicted SARS-COV-2 encoded microRNAs target NFKB, JAK/STAT and TGFB signaling pathways. Gene Rep 22: 101012.

126. Mehta P, McAuley DF, Brown M, Sanchez E, Tattersall RS, et al. (2020) HLH Across Speciality Collaboration, UK. COVID-19: consider cytokine storm syndromes and immunosuppression. Lancet 395(10229): 1033-1034.

127. Pacha O, Sallman MA, Evans SE (2020) COVID-19: a case for inhibiting IL-17?. Nat Rev Immunol 20(6): 345-346.

128. Li Q, Gu Y, Tu Q, Wang K, Gu X, et al. (2016) Blockade of Interleukin-17 Restrains the Development of Acute Lung Injury. Scand J Immunol 83(3): 203-11.
129. Zhao Y, Kilian C, Turner JE, Lidia Bosurgi, Kevin Roedl, et al. (2021) Clonal expansion and activation of tissue-resident memorylike Th17 cells expressing GM-CSF in the lungs of severe COVID-19 patients. Sci Immunol 6(56): eabf6692.

130. Bacchi S, Palumbo P, Sponta A, Coppolino MF (2012) Clinical pharmacology of non-steroidal anti-inflammatory drugs: a review. Anti-inflamm Antiallergy Agents Med Chem 11(1): 52-64.

131. Jasiecka A, Maślanka T, Jaroszewski JJ (2014) Pharmacological characteristics of metamizole. Pol J Vet Sci 17(1): 207-14

132. Collares EF, Troncon LEA (2019) Effects of dipyrone on the digestive tract. Braz J Med Biol Res 52(2): e8103.

133. Rudin D, Spoendlin J, Cismaru AL, Liakoni E, Bonadies N, et al. (2019) Metamizole-associated neutropenia: Comparison of patients with neutropenia and metamizole-tolerant patients. Eur J Intern Med 68: 36-43.

134. Navarro Zorraquino M (1974) Aportación al estudio de la fibrinólisis, función plaquetaria y terapéutica antiagregante bajo la influencia del acto quirúrgico. Tesis Doctoral. Universidad de Zaragoza. Ed.: Hernández-M. DL.Z-761-74. Zaragoza 1975: 32-33,117-122,128.

135. Navarro-Zorraquino M, Lozano Mantecón R, Cornudella R, Salinas JC (1977) Changes in serum immunoglobulins, fibrinolysis and platelet function after major surgical operation. In: Louros NC (Edt.)., Proceedings of the Biennial World Congress of the International College of Surgeons. Vol. III Atenas, pp. 1126-1128.

136. Navarro M, Lasierra J, Lozano R, Viladés E (1975) Acción de la oxquinazina metilada sobre la agregación plaquetaria en el período postoperatorio. Medicina Clínica 65: 511-514.

137. Wang W, Xu Y, Gao R, Lu R, Han K, et al. (2020) Tan W. Detection of SARS-CoV-2 in different types of clinical specimens. JAMA 323(18): 1843-1844.

138. Tay MZ, Poh CM, Rénia L, MacAry PA, Ng LF (2020) The trinity of COVID-19: immunity, inflammation and intervention. Nat Rev Immunol 28: 1-2.

139. Rea IM, Gibson DS, McGilligan V, McNerlan SE, Alexander HD, et al. (2018) Age and age-related diseases: role of inflammation triggers and cytokines. Front Immunol 9: 586.

140. Schmitt V, Rink L, Uciechowski P (2013) The Th17/Treg balance is disturbed during aging. Exp Gerontol 48(12): 1379-86.

141. Martinez MA (2020) Compounds with Therapeutic Potential against Novel Respiratory 2019 Coronavirus. Antimicrob Agents Chemother 64(5): e00399-20.

142. Cao L, Goreshnik I, Coventry B, Case JB, Miller L, et al. (2020) De novo design of picomolar SARS-CoV-2 miniprotein inhibitors. Science 370(6515): 426-431.

143. Pfrepper C, Deters S, Metze M, Siegemund R, Gockel I, et al. (2019) Metamizole inhibits arachidonic acid-induced platelet aggregation after surgery and impairs the effect of aspirin in hospitalized patients. Eur J Clin Pharmacol 75(6): 777-784. 
ISSN: 2574-1241

DOI: $10.26717 /$ BJSTR.2021.39.006232

Marta Navarro-Zorraquino. Biomed J Sci \& Tech Res

(C) (P) This work is licensed under Creative Commons Attribution 4.0 License

Submission Link: https://biomedres.us/submit-manuscript.php

$\begin{array}{ll}\text { BIOMEDICAL } & \begin{array}{l}\text { Assets of Publishing with us } \\ \text { RESEARCHES }\end{array} \\ \text { - Global archiving of articles } \\ \text { - Immediate, unrestricted online access } \\ \text { - Rigorous Peer Review Process } \\ \text { - Authors Retain Copyrights }\end{array}$

